\title{
Estimating Changes in Forest Attributes and Enhancing Growth Projections: a Review of Existing Approaches and Future Directions Using Airborne 3D Point Cloud Data
}

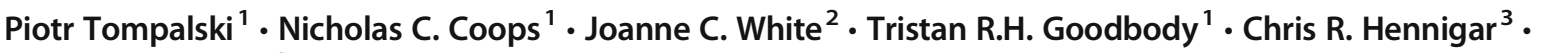 \\ Michael A. Wulder ${ }^{2}$ Jarosław Socha ${ }^{4} \cdot$ Murray E. Woods $^{5}$
}

Accepted: 14 January 2021

(C) The Author(s) 2021, corrected publication 2021

\begin{abstract}
Purpose of Review The increasing availability of three-dimensional point clouds, including both airborne laser scanning and digital aerial photogrammetry, allow for the derivation of forest inventory information with a high level of attribute accuracy and spatial detail. When available at two points in time, point cloud datasets offer a rich source of information for detailed analysis of change in forest structure.

Recent Findings Existing research across a broad range of forest types has demonstrated that those analyses can be performed using different approaches, levels of detail, or source data. By reviewing the relevant findings, we highlight the potential that biand multi-temporal point clouds have for enhanced analysis of forest growth. We divide the existing approaches into two broad categories - - approaches that focus on estimating change based on predictions of two or more forest inventory attributes over time, and approaches for forecasting forest inventory attributes. We describe how point clouds acquired at two or more points in time can be used for both categories of analysis by comparing input airborne datasets, before discussing the methods that were used, and resulting accuracies.

Summary To conclude, we outline outstanding research gaps that require further investigation, including the need for an improved understanding of which three-dimensional datasets can be applied using certain methods. We also discuss the likely implications of these datasets on the expected outcomes, improvements in tree-to-tree matching and analysis, integration with growth simulators, and ultimately, the development of growth models driven entirely with point cloud data.
\end{abstract}

Keywords Lidar $\cdot$ ALS $\cdot$ DAP $\cdot$ Site index $\cdot$ Change detection

This article is part of the Topical Collection on Remote Sensing

Piotr Tompalski

piotr.tompalski@ubc.ca

1 Integrated Remote Sensing Studio, Department of Forest Resources Management, University of British Columbia, 2424 Main Mall, Vancouver, BC V6T 1Z4, Canada

2 Canadian Forest Service (Pacific Forestry Centre), Natural Resources Canada, 506 West Burnside Road, Victoria, BC V8Z 1M5, Canada

3 New Brunswick Department of Natural Resources, 1350 Regent St, Fredericton, NB E3C 2G6, Canada

4 Department of Forest Resources Management, Faculty of Forestry, University of Agriculture in Krakow, Al. 29-listopada 46, 31-425 Krakow, Poland

5 Ontario Ministry of Natural Resources and Forestry (Retired), 3301 Trout Lake Road, North Bay, ON P1A 4L7, Canada

\section{Introduction}

Information on forest resources is important for forest planning and management activities. Sustainable forest management decisions require accurate information on the extent, quality, and quantity of the available resource, while future growth projections form the basis of long-term planning [1, 2]. Forest growth and yield projections are also key in estimating biomass accumulation and the dynamics of forest carbon pools [3-7]. Conventionally, foresters have utilized a number of biometric and statistical approaches to characterize individual tree- and stand-level growth, resulting in growth simulators for projecting current tree and stand conditions into the future.

The use of remote sensing technologies for forest inventory, specifically airborne laser scanning (ALS) and digital aerial photogrammetry (DAP), has become widespread in research and operational forestry [8]. DAP data generated 
through the application of stereo or multi-image matching algorithms are capable of providing similar 3D information to ALS point clouds. The accuracy and fine spatial detail afforded by ALS data can bridge the gap between strategic, tactical, and operational forest information needs [9]. DAP provides an alternative source of $3 \mathrm{D}$ information that offers comparable or lower accuracies when compared to that of ALS data for area-based modeling, with the potential for cost savings in data acquisition [10-14]. When utilized in an enhanced forest inventory (EFI), where 3D remote sensing data and spatial derivatives are incorporated with traditional ground plot data to generate wall-to-wall forest attribute predictions and maps, estimates provided by ALS and DAP have advantages over conventional polygonal stand-level inventory datasets including increased spatial detail and accuracy $[15,16]$. These remote sensing-based inventories do however have limitations that are of particular relevance for growth modeling, particularly around attributes that are obtained via planting records (e.g., age) or visual interpretation (e.g., tree species composition).

Discrete return ALS systems (with footprint sizes of 0.1$2 \mathrm{~m}$ ) typically record up to five returns [17] and are optimized for the derivation of submeter accuracy terrain surface heights [18]. These systems yield a cloud of three dimensionally registered points wherein lower points most often represent the ground surface while those above ground represent undifferentiated vegetation in a forest environment. DAP point clouds characterize forest structure in a manner that is fundamentally different to ALS in that they only describe the outer envelope of the forest canopy, lacking information about internal stand structure and terrain. For this reason, DAP is reliant on colocated ALS-derived terrain data to normalize vegetation height [8].

After point clouds have been normalized by the ALScharacterized ground surface, two different levels of detail are often used to derive forest inventory information. At the individual tree level, tree segmentation algorithms are applied to the point cloud, or a rasterized canopy height model, to identify treetops and delineate their crowns. Subsets of point clouds within individual crowns are then analyzed to estimate single-tree attributes. Alternately, at a cell or area level, a grid is overlaid on the area of interest. Descriptive statistics (i.e., metrics) from point clouds within each grid cell are then calculated and used as independent variables during modeling. The process holds that co-located field-measured attributes are related to the representative metrics (describing the vertical and spatial distribution of points in the cell; e.g., height percentiles, cover proportions, and related variability) and enable the development of predictive models. As a result, two levels of detail correspond to the two approaches that are currently applied in point cloud-based forest inventories - the individual tree approach (ITA) and area-based approach (ABA), respectively [19-21]. Regardless of the type of approach used, both provide detailed information on a range of tree or forest attributes from the time of data acquisition. One key aspect that is often missing in these single time frame ALS-based estimates however is the prediction of growth and stand conditions into the future.

While research and operational focus has primarily been on the estimation of forest structural attributes at the time of data acquisition, focus is increasingly shifting to predictions of tree- or stand-level forest growth [22-24]. Several factors are driving this shift. First and foremost, both research and operational use of ALS data were constrained to a single data acquisition, either as a function of cost, sensor availability, or both. Second, linking ALS or DAP estimates at a single point in time to biometric models of stand growth (such as yield tables) is complex, especially given the variety of attributes required for base growth and future yield calculations, some of which are not readily derived using ALS or DAP data alone. In addition, while ALS or DAP data provide estimates of forest attributes used in tree- or stand-level growth simulators (e.g., height, diameter at breast height), the statistical representations of tree and stand attributes likely differ from those of conventional field-based measurements, resulting in the need for the recalibration of growth simulators to use point cloud derivatives. Finally, as the ABA has become increasingly operational, and researchers and forest managers have demonstrated the benefits of the technology for forest inventory and operations, ALS acquisitions are becoming increasingly common, expanding the availability and extent of multitemporal point cloud datasets beyond those limited to research sites. The added temporal dimension of point clouds acquired at two (or more) points in time offers additional capabilities to analyze change in forest conditions and characterize forest growth.

One of the first studies utilizing point cloud data acquired at two points in time was Hyyppä et al. [25] who used bitemporal ALS data to estimate height growth at an individual tree level. Existing literature has since provided examples of how bi- or multi-temporal ALS data can be used to detect and characterize changes in height $(\Delta \mathrm{H})$, basal area $(\Delta \mathrm{BA})$, volume $(\Delta \mathrm{V})$, and aboveground biomass ( $\Delta \mathrm{AGB})$ e.g., [14-16]. Further, recent examples of applications of DAP in forestry demonstrate that these data can be used as an alternative to ALS and, when integrated with ALS acquired at different times, can be used to study temporal changes $[8,12$, 26-29].

The methods that have been applied to estimate growth vary markedly and are related to the scale at which the analysis is performed (e.g., tree or cell level), the statistical models used to predict growth, and the type of point cloud data being used. In a previous review, McRoberts et al. [30] summarized existing approaches of characterizing change in forest attributes using multi-temporal ALS data. Focusing on the current research (about 20 papers compared to the over 50 reviewed herein), trends on the development of methods that could be 
used to determine change were described. Building on McRoberts et al. [30], this review describes novel approaches, highlights recent studies incorporating both ALS and DAP data, and includes studies that use multiple data acquisitions and not just data from two time steps only. From these findings, we then demonstrate how point cloud informed estimates of change in forest attributes can be used to forecast future forest stand conditions and characterize forest growth.

In our review, we summarize recent studies that demonstrate the use of ALS or DAP datasets to examine changes in forest conditions or structure through time, synthesizing lessons learned and highlighting current research gaps. We then provide an overview of forestry-related point cloud-based routines to characterize change in forest attributes and demonstrations of how point cloud data can be integrated with growth simulators. Finally, we discuss challenges related to bi- or multi-temporal analyses ending with recommendations and future directions.

\section{Approaches to Estimating Tree or Stand Growth Using Point Cloud Data}

Approaches using ALS or DAP data in the context of forest growth fall into two major categories (Fig. 1):

1. Retrospectively estimating growth rates based on two or more measurements in time. This approach includes several different methods to characterize change between data acquisitions including point cloud-based change detection, as well as cell- and tree-level estimates of growth. The majority of reviewed studies fall into this category, with multiple examples demonstrating the advantages and disadvantages of applied approaches.

2. Integrating ALS and DAP data, or attribute estimates derived from these data, into models that forecast contemporary forest attributes into the future. This approach includes methods that incorporate observed growth rates in forest attributes from point clouds into existing forest productivity models (i.e., site index) and growth simulators, as well as leveraging change information to develop new models for forecasting future stand attributes.

\section{Retrospectively Estimating Growth Based on Observations at Two or More Points in Time}

Many of the reviewed studies described a number of methods of how bi- or multi-temporal point clouds can be used to retrospectively estimate forest growth. Methods can be grouped into three categories depending on the level of detail (Fig. 2): CHM differencing, analysis at the cell level (areabased approach, ABA), and analysis at the individual tree level. While the level of detail is clearly defined in the last two categories (cell- and tree-level analysis), this is very often not the case when analyses are based on differencing point cloud-derived metrics or canopy height models (CHMs).

\section{CHM Differencing}

The most straightforward case of using multi-temporal point cloud datasets to characterize growth is detecting changes in the CHMs, or from changes in point cloud metrics directly (Fig. 2). When comparing CHMs, a set of height layers are derived for each time step providing an opportunity to quantify the change and growth in height. For example, Vastaranta et al. [12] used an ALS-derived CHM for T1 and two CHMs derived for T2 (ALS- and DAP-derived) to estimate $\Delta \mathrm{H}$ at plot level. The agreement between change in CHM using both data pairs $\left(\mathrm{ALS}_{\mathrm{T} 1}+\mathrm{ALS}_{\mathrm{T} 2}\right.$ or $\left.\mathrm{ALS}_{\mathrm{T} 1}+\mathrm{DAP}_{\mathrm{T} 2}\right)$ was found to be high with a correlation coefficient of 0.71 .

Noordermeer et al. [31] used bitemporal ALS data to identify four different categories of change: change in dominant height (increase, decrease), change in aboveground biomass (increase, decrease), forest disturbances (undisturbed, disturbed), and forest management (untouched, partial harvest, clearcut). An automated kNN approach was used to identify the changes at the plot level, with ALS metrics used as independent predictor variables. Leave-one-out cross-fold validation revealed overall accuracies between 88 and 96\%, with highest overall accuracy reported for change in dominant height.

\section{Area-Based Estimation of Growth}

The majority of papers and approaches estimating growth at the cell level initially focused on a single attribute, with $\Delta \mathrm{H}$ being the focus in initial publications [32-34]. As the technology has advanced, more studies have focused on $\triangle \mathrm{AGB}$, which is the most studied attribute across all research using point cloud data at cell level (Table 1, Fig. 3). Recent studies have focused on the potential to estimate change for multiple attributes in unison [55, 57, 59]. Five out of 29 studies used point cloud data acquired at more than two points in time [33, $34,43,53,60]$, while only four studies did not use ALS time series datasets. Goodbody et al. [51] and Tompalski et al. [59] combined ALS data acquired at T1 with DAP data collected at T2 using remotely piloted aircraft systems (RPAS, also known as unmanned aircraft systems) and large format cameras, respectively. Stepper et al. [48] used DAP data acquired at T1 and $\mathrm{T} 2$ to characterize height change in highly structured mixedwood forests. $\triangle \mathrm{AGB}$ based on four DAP acquisitions was characterized by Price et al. [60]. These two examples are the only studies that relied on DAP data exclusively to characterize changes in forest attributes at a cell level through time; however in both studies, ALS-derived terrain was used for data normalization to aboveground heights. 


\section{Stand development through time}

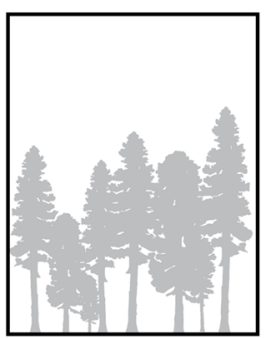

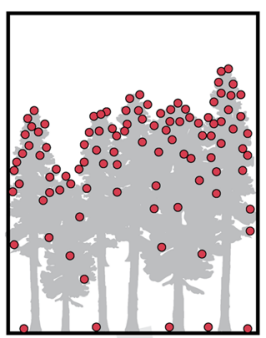

Acquisition 1

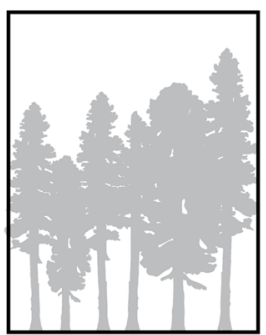

Acquisition 2

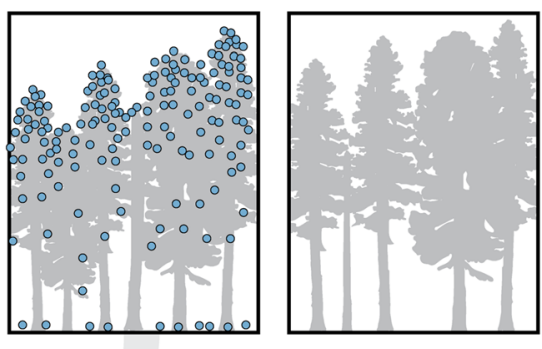

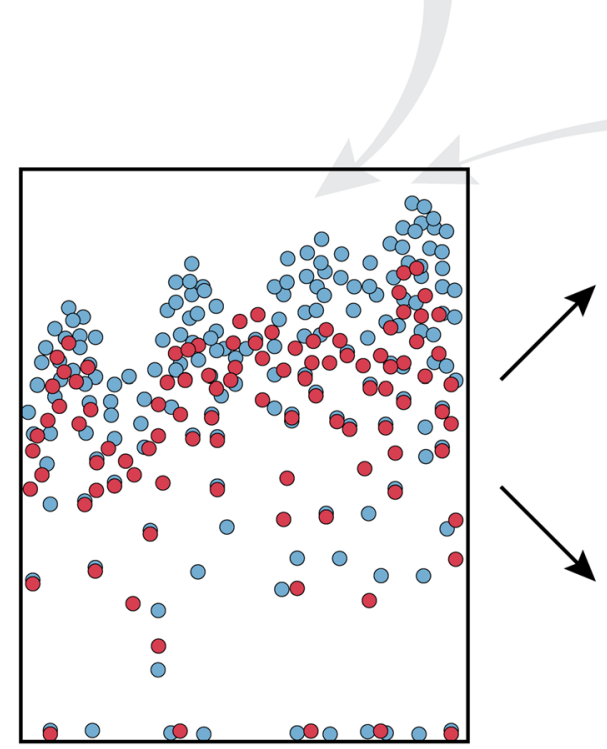

Fig. 1 Overview of the two approaches used to characterize change in forest attributes. The first approach utilizes two or more point cloud datasets to retrospectively estimate growth rates. In the second

Two methods for estimating stand growth or mortality using bi- or multi-temporal point cloud data, the indirect or direct methods, have been used for area-based modeling [e.g., 22, 24]. In the indirect method, the change in forest attributes is quantified by developing separate, independent predictive models for the first time step (T1) and the second time step (T2) and calculating the difference between the two attribute predictions (in the case of bitemporal data). In the direct method, change is estimated by developing a single model that uses the field-measured change between two observations as the dependent variable and change in point cloud metrics used as predictors.

There are a number of studies that demonstrate the applicability of both direct and indirect approaches for estimating change in forest attributes (Table 1). Among the multiple examples of studies that compared both of the approaches, there are some that have recommended the indirect method e.g., $[28,30]$ and some the direct method [e.g., 15, 26, 31, 32, 53]. There is currently no consensus on which approach provides more accurate estimates of stand growth under different stand conditions, point cloud data characteristics [54], or time difference between acquisitions. However, based on studies

\author{
Retrospectively estimating growth \\ point cloud-based change estimates \\ area-based or tree-level detail \\ -direct / indirect approaches
}

Forecasting forest attributes into the future

- growth simulators and productivity models - plot / curve matching approaches - developing growth functions

approach, the point cloud datasets or derived attribute estimates are integrated into models that forecast contemporary forest attributes into the future

listed in Table 1 that applied both the direct and indirect approach in the same study, 11 reported the direct approach as more accurate and 4 the indirect as more accurate. We did not notice any relationship with time difference between point cloud data acquisitions for studies that recommended the direct or indirect approach - the average time difference was 6.60 and 6.75 years, respectively. Mauro et al. [57] noted that the indirect approach could be less sensitive to spatial extrapolation and more accurate at the stand level. However, taking diversity in reported results into account, the most accurate approach for estimating change in forest attributes must be determined independently for each study and may be dependent upon stand conditions and management considerations.

In terms of model development, the direct approach is markedly simpler than the indirect and offers faster model development and fitting [57]. Error for the direct approach is derived from a single model [56], while error in the indirect approach is compounded from individual model errors used to estimate the attribute at T1 and T2 [56, 59]. The direct approach is more computationally simple, requiring a relationship between the change in point cloud metrics and change in 
Forest stand at two points in time

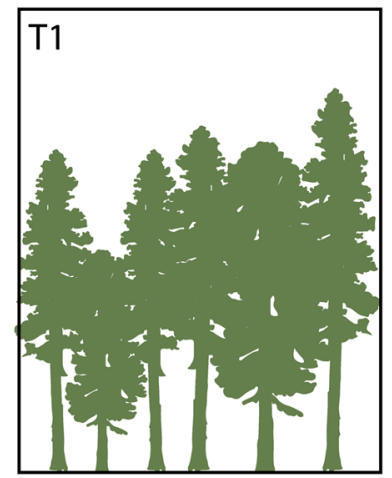

CHM differencing

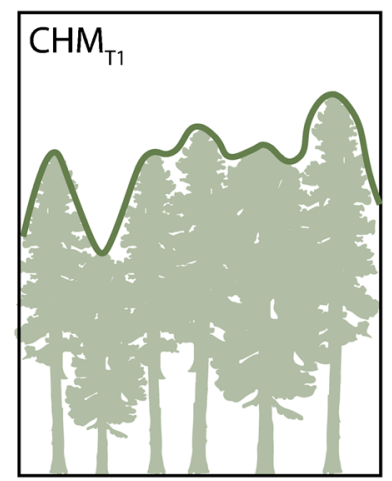

Area-based analysis

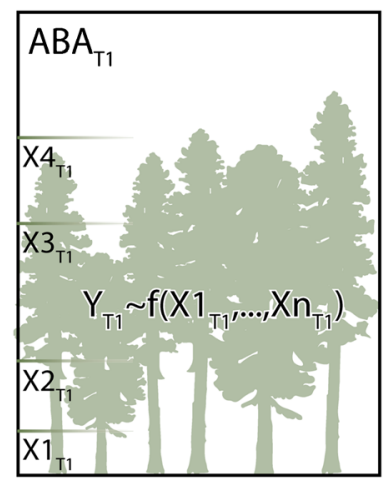

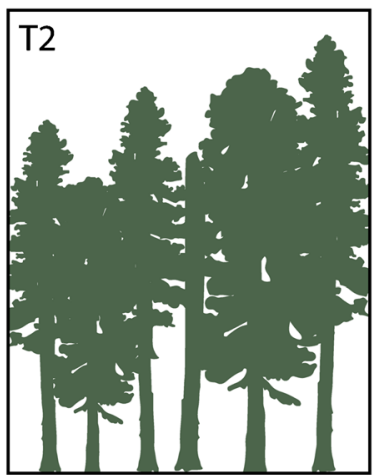
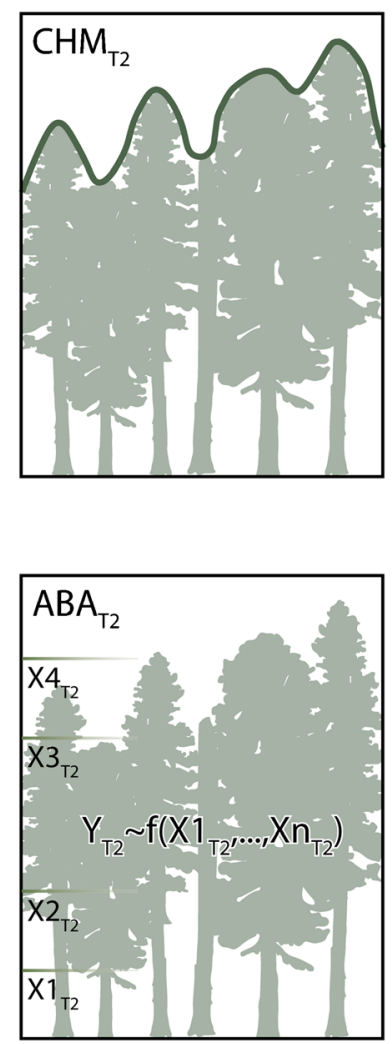

Individual tree-level analysis
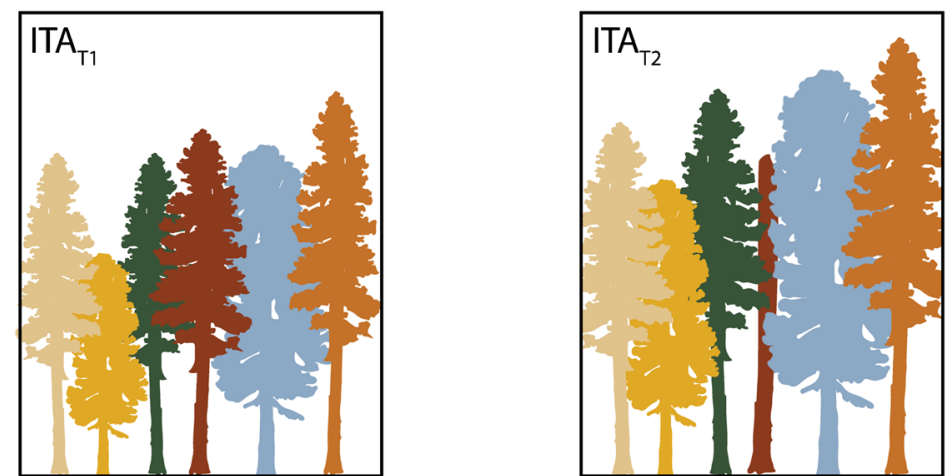
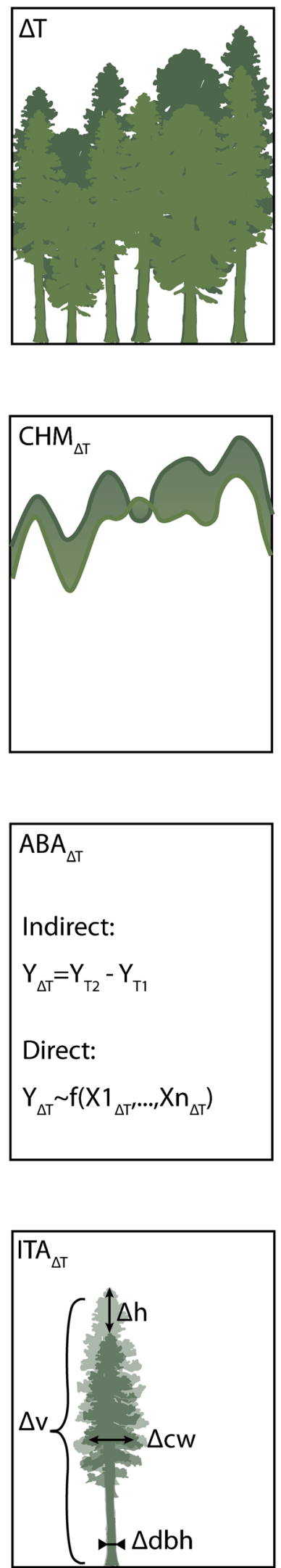

Fig. 2 Approaches used to estimate past change in forest inventory attributes. Growth can be estimated using CHM differencing, area-based, and individual tree-level analysis 


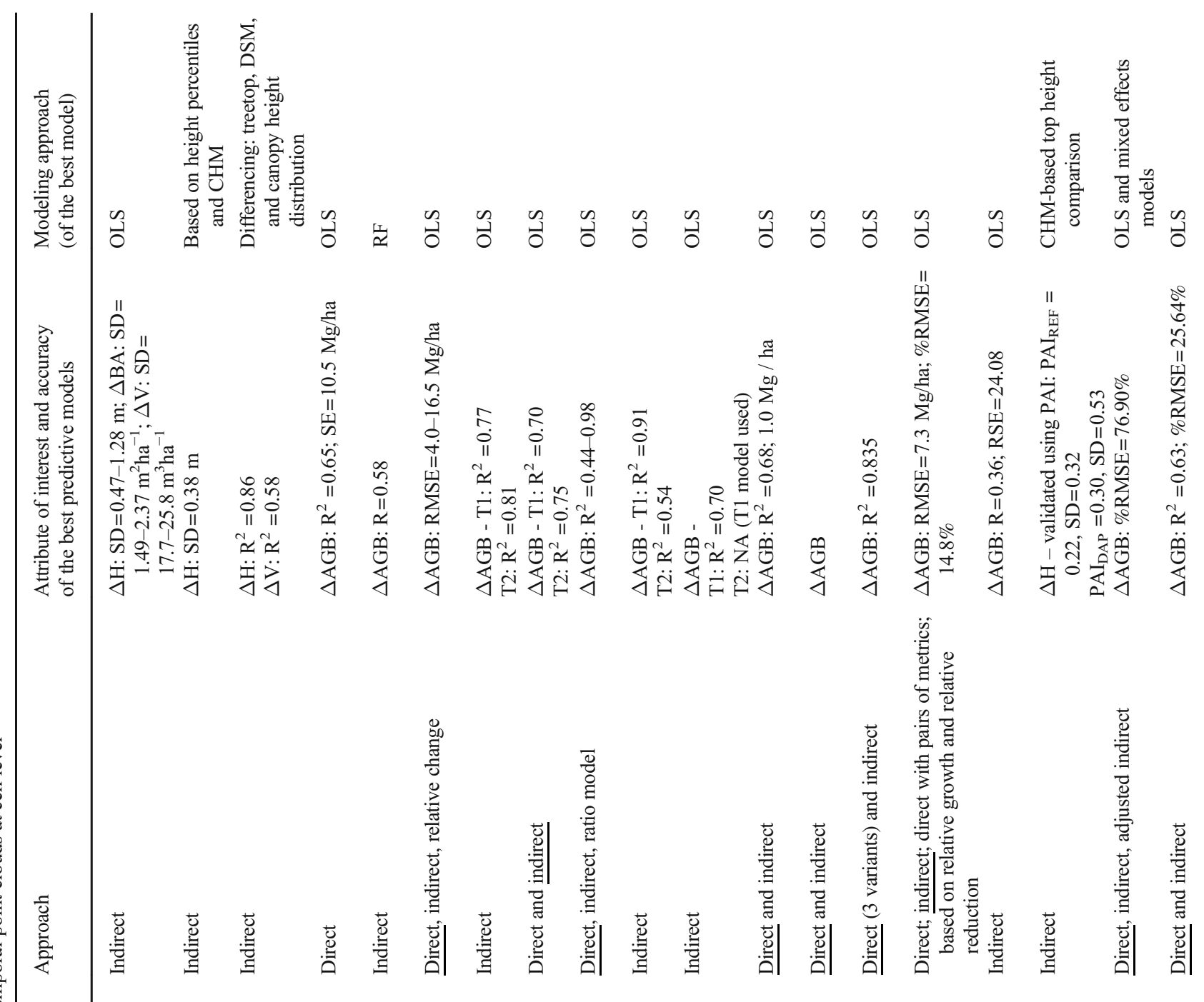

¿্ণ

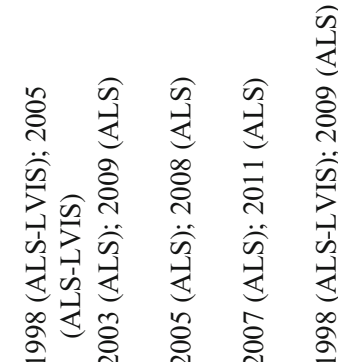
这 宅

ڤे 


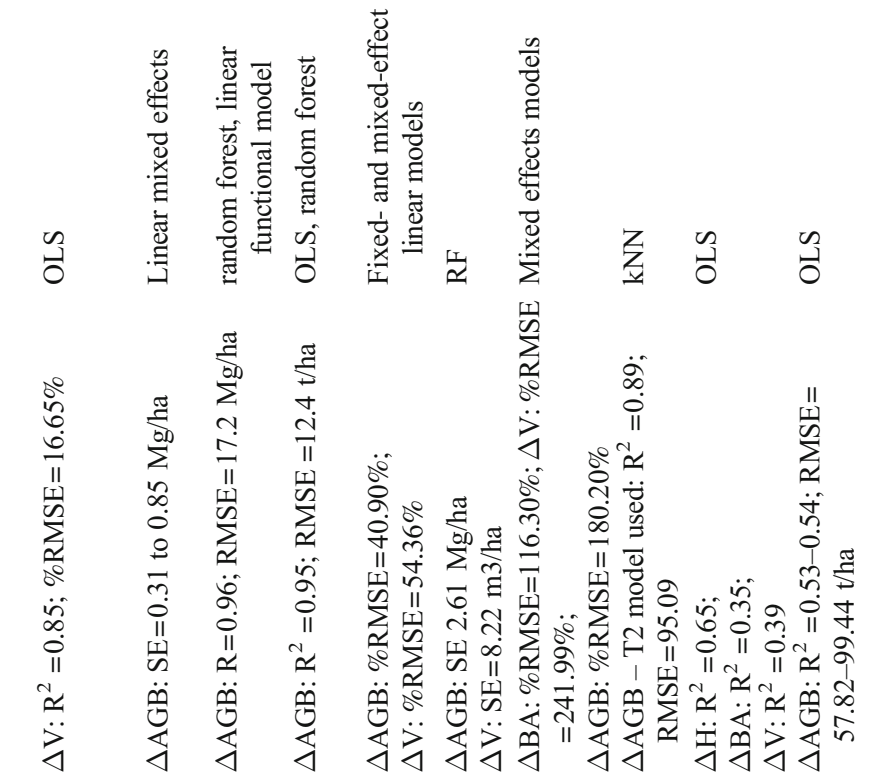

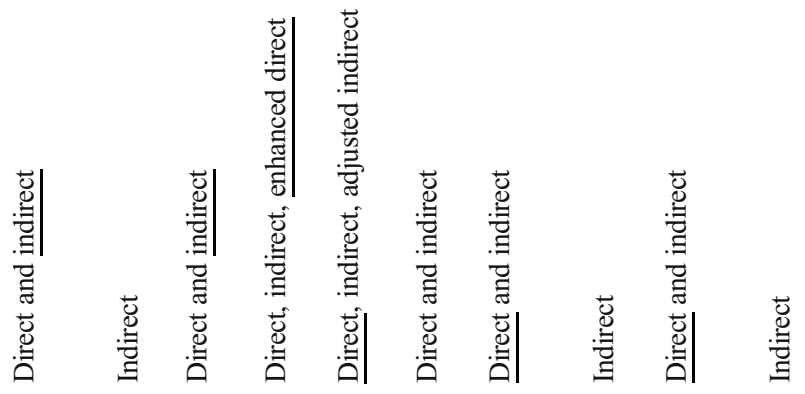

के

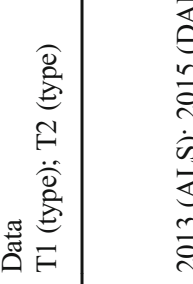

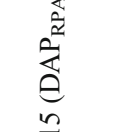

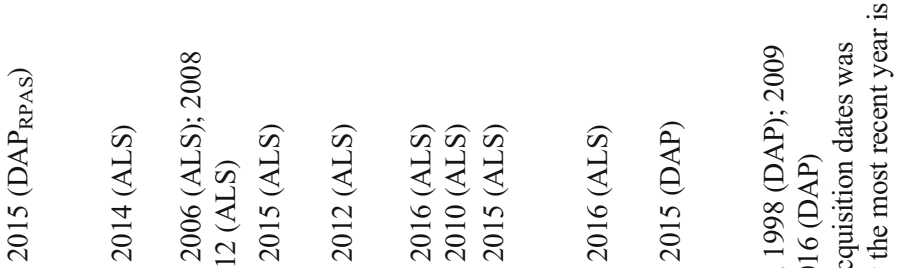

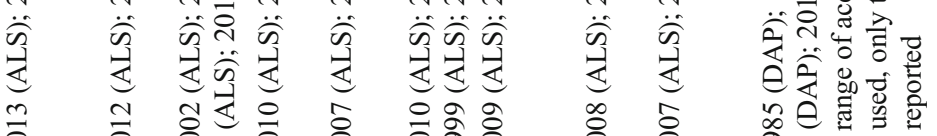




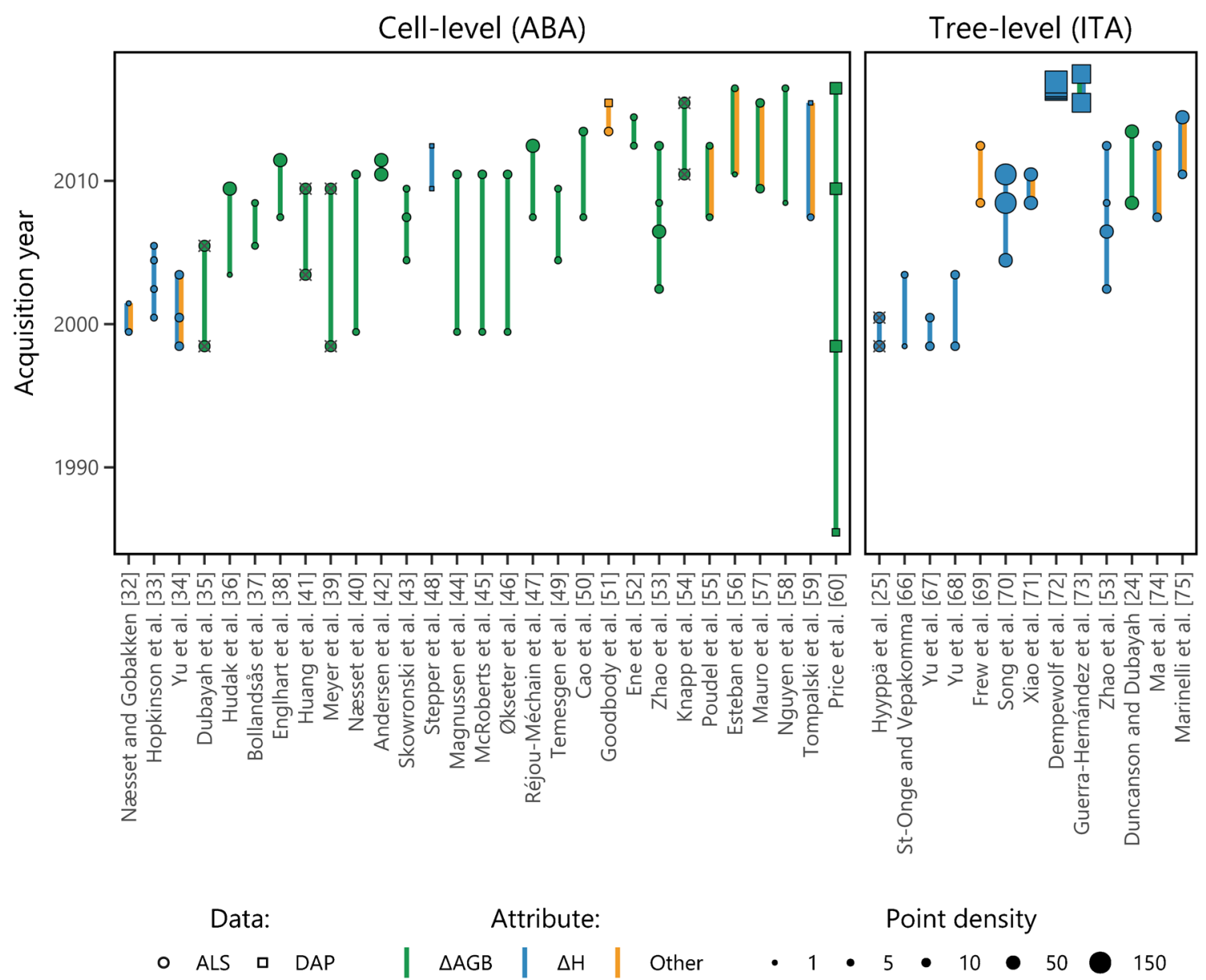

Fig. 3 Summary of studies describing the use of bi- or multi-temporal point cloud data for estimating change in forest attributes at the cell and tree level. Circles and squares indicate the data acquisition year for ALS and DAP, respectively. Colors indicate attributes of interest. $\triangle \mathrm{AGB}$, change in above ground biomass; $\Delta \mathrm{H}$, change in height (plot or tree

forest attribute. Establishing such relationships does however require that the correlation between point cloud metrics and plot-level attribute change is strong. For example, Ene et al. [52] could not use the direct approach in their study as the time difference between the two ALS acquisitions was 2 years and the correlation between metrics and attribute change was very weak. Similarly, in the study by Goodbody et al. [51] where the time difference between point cloud data acquisition was 2 years, authors reported very large errors for the direct approach. In these situations, where the number of years between acquisitions is limited, growth does not likely exceed error in measurement and modeling [18]. The main advantage of the indirect approach is that it utilizes the predictions derived for the beginning and end of the time interval and therefore can be supported with the well-studied relationship between point cloud metrics and forest stand attributes [54].

Because the indirect method of estimating change in forest attributes is based on T1 and T2 estimates, it is straightforward to apply when estimates already exist. For example, Hudak et al. [36] used the indirect approach to calculate 6-year level); other, change in other attributes, including change in volume, change in crown volume, change in crown area, and change in basal area. The " $x$ " symbol indicates that point density was not available (e.g., Land, Vegetation, and Ice Sensor (LVIS) data)

biomass change in mixed conifer forest in Idaho, USA, using bitemporal ALS data. Individual random forest models of biomass were developed for $\mathrm{T} 1$ and $\mathrm{T} 2$ and differentiated to derive cell-level wall-to-wall predictions of biomass change. The Pearson correlation coefficient between the observed and estimated biomass change was 0.58 . Similar approaches were used in several other studies, for instance, Englhart et al. [38], Réjou-Méchain et al. [47], and Ene et al. [52] used the indirect approach to estimate $\triangle \mathrm{AGB}$ in tropical forest environments. Interestingly, Réjou-Méchain et al. [47] developed the linear regression model to predict AGB using $\mathrm{T} 2$ data only and then applied it to T1 and T2 data, although the accuracy of the $\triangle \mathrm{AGB}$ was relatively low, with a correlation coefficient of $0.36\left(R^{2}=0.13\right)$. A similar approach was used by Nguyen et al. [58], who investigated the potential of bitemporal ALS data and single-date inventory data to estimate $\triangle \mathrm{AGB}$ in ashdominated forest stands in Victoria, Australia. They developed a single predictive model for AGB at T2 and applied it to ALS data acquired at T1 and T2 with 8-year time difference, however, do not report accuracy of $\Delta \mathrm{AGB}$ estimates. 
Table 2 Studies that estimated change in forest attributes using bi- or multi-temporal point clouds at tree level

\begin{tabular}{|c|c|c|c|}
\hline Reference & Location; forest type & Data & $\begin{array}{l}\text { Attribute of interest and } \\
\text { accuracy } \\
\text { of the best predictive models }\end{array}$ \\
\hline Hyyppä et al. [25] & Finland; Boreal & 1998 (ALS); 2000 (ALS) & $\Delta \mathrm{H}: \mathrm{SE}<5 \mathrm{~cm}$ at stand level \\
\hline $\begin{array}{l}\text { St-Onge and Vepakomma } \\
\text { [66] }\end{array}$ & Quebec, Canada; Boreal & 1998 (ALS); 2003 (ALS) & $\Delta \mathrm{H}: \mathrm{MD}=0.42 ; \mathrm{MAD}=1.09$ \\
\hline Yu et al. [67] & Finland; Boreal & 1998 (ALS); 2000 (ALS) & $\begin{array}{l}\Delta \mathrm{H}: \mathrm{SE}=10-15 \mathrm{~cm}(\text { at plot } \\
\text { level) }\end{array}$ \\
\hline Yu et al. [68] & Finland; Boreal & 1998 (ALS); 2003 (ALS) & $\Delta \mathrm{H}: \mathrm{R}^{2}=0.68, \mathrm{RMSE}=0.43 \mathrm{~m}$ \\
\hline Frew et al. [69] & Oregon, USA; Douglas-fir dominated & 2008 (ALS); 2012 (ALS) & $\Delta \mathrm{CV}: \mathrm{MD}=-2.02 \mathrm{~m}^{3}$ \\
\hline Song et al. [70] & Japan; Broad-leaf park & 2004 (ALS); 2008 (ALS); 2010 (ALS) & $\Delta \mathrm{H}: \mathrm{R}>0.8$ (at plot level) \\
\hline Xiao et al. [71] & Netherlands; Broadleaf & 2008 (ALS); 2010 (ALS) & $\begin{array}{l}\Delta \mathrm{H} ; \Delta \mathrm{CA} ; \Delta \mathrm{CV} \text { (no validation } \\
\text { of } \\
\text { change in attributes) }\end{array}$ \\
\hline Dempewolf et al. [72] & Germany; Mixed temperate & $\begin{array}{l}27.05 .2016\left(\mathrm{DAP}_{\text {RPAS }}\right) ; 08.07 .2016 \\
\left(\mathrm{DAP}_{\text {RPAS }}\right) ; 19.08 .2016\left(\mathrm{DAP}_{\text {RPAS }}\right) \\
22.11 .2016\left(\mathrm{DAP}_{\mathrm{RPAS}}\right)\end{array}$ & $\begin{array}{l}\Delta \mathrm{H} \text { (no validation of change } \\
\text { in attributes) }\end{array}$ \\
\hline $\begin{array}{l}\text { Guerra-Hernández et al. } \\
\text { [73] }\end{array}$ & Portugal; Pinus pinea plantation & $2015\left(\mathrm{DAP}_{\mathrm{RPAS}}\right) ; 2017\left(\mathrm{DAP}_{\mathrm{RPAS}}\right)$ & $\begin{array}{l}\Delta \mathrm{H}: 0.45 \mathrm{~m} \pm 0.12 \mathrm{~m} ; \Delta \mathrm{AGB}: \\
198.7 \pm 93.9 \mathrm{~kg}\end{array}$ \\
\hline Zhao et al. [53] & Scotland; Sitka spruce dominated & $\begin{array}{l}2002 \text { (ALS); } 2006 \text { (ALS); } 2008 \text { (ALS); } 2012 \\
\quad \text { (ALS) }\end{array}$ & $\begin{aligned} \Delta \mathrm{H}: \mathrm{R} & =0.67, \mathrm{RMSE}=0.91 \mathrm{~m} \\
\text { Bias } & =0.02 \mathrm{~m}\end{aligned}$ \\
\hline $\begin{array}{l}\text { Duncanson and Dubayah } \\
\text { [24] }\end{array}$ & $\begin{array}{l}\text { California, USA; Fir and pine } \\
\text { dominated }\end{array}$ & 2008 (ALS); 2013 (ALS G-LiHT) & $\triangle \mathrm{AGB}: \mathrm{SE} \sim 80 \%$ \\
\hline Ma et al. [74] & California, USA; Conifer dominated & 2007/2008 (ALS); 2012/2013 (ALS) & $\begin{array}{l}\Delta \mathrm{H}-\mathrm{T} 1: \text { bias }=-0.43 \mathrm{~m}, \\
\mathrm{RMSE}=0.82 \mathrm{~m} ; \mathrm{T} 2: \text { bias }= \\
-0.11 \mathrm{~m}, \mathrm{RMSE}=0.85 \mathrm{~m} \\
\Delta \mathrm{CA}, \Delta \mathrm{CV} \text { (no validation) }\end{array}$ \\
\hline Marinelli et al. [75] & $\begin{array}{l}\text { Italy (two study sites); Conifer } \\
\text { dominated }\end{array}$ & 2010/2012 (ALS); 2014/2015 (ALS) & $\begin{array}{l}\Delta \mathrm{H}, \Delta \mathrm{CA}, \Delta \mathrm{CV} \text { (no validation } \\
\text { of change in attributes) }\end{array}$ \\
\hline
\end{tabular}

$\mathrm{DAP}_{\mathrm{RPAS}}$ refers to DAP data acquired using remotely piloted aircraft systems

Dubayah et al. [35] were one of the few examples that applied the direct approach only. The authors used two LVIS (Land, Vegetation, and Ice Sensor) datasets acquired with 7-year difference to characterize $\triangle \mathrm{AGB}$ in Costa Rica. The reported accuracy $\left(R^{2}=0.65\right)$ is among the highest in the studies we report (Table 1); however, it is worth noting that LVIS is a full waveform instrument, whereas the majority of other studies in Table 1 have used small footprint, discrete return ALS. A modified version of the direct approach was tested by Bollandsås et al. [37]. Instead of using the differences in pairs of corresponding point cloud-based metrics, they predicted $\triangle \mathrm{AGB}$ directly using models that used pairs of corresponding metrics from each point in time as predictors. Økseter et al. [46] expanded these analyses further, adding two additional approaches of predicting change in forest attributes. They predicted $\Delta \mathrm{AGB}$ using models for relative growth rates between $\mathrm{T} 1$ and $\mathrm{T} 2$ and models for relative reduction rates between $\mathrm{T} 2$ and $\mathrm{T} 1$. Interestingly, none of the additional approaches were found to be more accurate compared to the standard indirect or direct approach.

Alternative approaches have also been proposed. Næsset et al. [40] used a new approach based on estimating the ratio of biomass change between $\mathrm{T} 2$ and $\mathrm{T} 1$ in addition to the direct and indirect approaches. In this method, models were developed to estimate biomass at $\mathrm{T} 1$ as well as for modeling the ratio between biomass in $\mathrm{T} 2$ and $\mathrm{T} 1$. The predictors included $\mathrm{T} 1$ point cloud metrics when $\mathrm{T} 1$ biomass was the response variable and ratios of $\mathrm{T} 2$ and $\mathrm{T} 1$ point cloud metrics when the biomass ratio was the response variable. Results showed that the simple linear models developed for the direct approach were most accurate, closely followed by the ratio approach.

An enhanced version of the indirect approach was tested by Temesgen et al. [49] and Poudel et al. [55]. In addition to direct and indirect approaches, a calibrated indirect approach was tested, in which the predicted change in stand attribute was calibrated with a simple linear regression. The calibrated indirect approach was markedly more accurate than the standard indirect approach (e.g., \%RMSE for $\triangle \mathrm{AGB}$ changed from 125.30 to $43.45 \%$ in Poudel et al. [55], approach A4 and A6, respectively). However, in both studies, the direct approach was the most accurate in estimating change, although the difference to the calibrated indirect was small.

McRoberts et al. [45] compared the accuracy of estimating the $\Delta$ AGB using the indirect method and three variants of the 
direct method. The three variants included (1) direct approach with the difference in point cloud metrics used as independent variables (e.g., $\Delta \mathrm{X} 1$ ); (2) direct approach with pairs of metrics (e.g., $\mathrm{X} 1_{\mathrm{T} 1}$ and $\mathrm{X} 1_{\mathrm{T} 2}$ ) with separate coefficients; and (3) direct approach with independent variables selected from $\mathrm{T} 1$ and $\mathrm{T} 2$ metrics without regard to pairing (e.g., $\mathrm{X} 1_{\mathrm{T} 1}$ and $\mathrm{X} 2_{\mathrm{T} 2}$ ). The indirect approach was found to be more accurate when compared to the traditional variant of the direct approach in which differences in metric pairs are used as independent variables. However, the two additional variants of the direct approach were found to be superior and provided the most accurate estimate of $\triangle \mathrm{AGB}$. The approach that is based on $\mathrm{T} 1$ and $\mathrm{T} 2$ metrics disregarding pairing is considerably easier to implement if independent variables are selected using stepwise techniques [45].

\section{Tree-Level Estimation of Growth}

Monitoring growth at an individual tree level offers insights into particular tree's growth response, as opposed to a cell or area-based average, allowing characterization of small changes in forest canopy, gap dynamics, and the tree growth to be assessed within stands or species. This additional level of detail allows further investigation into the relationship of tree growth or mortality with other factors including tree size, stem density, competition, or species composition. This information on changes in individual tree growth characteristics can be used to inform individual tree growth models or can be aggregated in some way to measure change in height at the stand level, recognizing that change in growth of a number of individual trees in stand is not necessarily synonymous with the average height increment of individual stands.

In order to detect changes in tree attributes, individual trees have to be identified (tree detection) and segmented (crown delineation). A large array of methods exist to perform both tasks [61-63] that typically include identification of local maxima in the CHM or the raw point cloud, which are then used as seeds in a region growing algorithms $[64,65]$. The majority of studies presenting individual tree-level analysis of growth (Table 2, Fig. 3) focus on changes in tree height [24, 53, 68, 70, 76]. Zhao et al. [53] used multi-temporal ALS data to estimate height growth of individual trees in a Sitka sprucedominated stand. They found that individual tree height growth could only be estimated if point cloud-based tree heights were corrected for bias. Without correction, ALSderived tree heights had a noticeable bias of $-1.5 \mathrm{~m}$ and the estimated height growth values were unrealistic. When corrected, a sub-annual height growth could be detected (RMSE $=0.91, R=0.67)$. The authors found that the empirical correction model was not needed if the ALS point density was greater than approximately 7 points $/ \mathrm{m}^{2}$.

A smaller set of studies have demonstrated how different tree attributes can be tracked over time based on point cloud data (Fig. 3). For example, Ma et al. [74] used bitemporal ALS data to quantify tree competition, $\Delta \mathrm{H}$, change in crown area $(\Delta \mathrm{CA})$, and $\Delta \mathrm{V}$, for 114,000 individual trees in two coniferdominant Sierra Nevada forests. Guerra-Hernández et al. [73] used bitemporal $\mathrm{DAP}_{\mathrm{RPAS}}$ point clouds to monitor change in $\Delta \mathrm{H}$ and $\Delta \mathrm{AGB}$ with a 2 -year interval between data acquisitions. They report the mean annual change of $0.45 \mathrm{~m}$ and $198.7 \mathrm{~kg}$ for $\mathrm{H}$ and AGB, respectively, with standard deviation (SD) of differences equal to $0.12 \mathrm{~m}$ and $93.9 \mathrm{~kg}$, respectively. However, authors also report that there were statistically significant differences between DAP-derived and reference changes in tree attributes.

Frew et al. [69] demonstrated a method to estimate changes in crown volume $(\Delta \mathrm{CV})$ based on multi-temporal ALS data. Authors used 3D convex hulls to calculate volumes of Douglas-fir crowns at T1 (2008) and T2 (2012). They report that the difference between ALS-derived change in crown volume and expected crown volume growth was not statistically different ( $p$ value $=0.85$ ). Frew et al. [69] manually detected and measured the trees directly on point clouds, focusing on estimating $\Delta \mathrm{CV}$ only and avoiding the influence of automatic tree detection methods and tree-to-tree matching between data acquisitions. An interesting approach to quantify changes in $\Delta \mathrm{H}$ and $\Delta \mathrm{CV}$ was presented by Marinelli et al. [75], though no empirical results are presented. The authors describe a hierarchical approach that first detects large changes in the forest canopy and then identifies changes at the individual tree level and reports low false and missed alarm rates for both large changes and the tree detection phase.

While tree-level approaches are more detailed, they bring additional challenges compared to analysis at the cell level. The overall success of the individual tree-based growth assessment depends on a multitude of factors including detection, tree-to-tree matching, and attribute estimation. For example, due to the greater overall complexity when compared to ABA or stand-level analysis, individual tree detection cannot be reliably applied when point density is low [53]. Other limitations include the inconsistency of detecting trees and a common issue is that dominant and codominant trees are detected with markedly higher accuracy than intermediate or suppressed trees [63].

One of the key limitations is the need for consistent detection and mapping of individual tree crowns for each ALS or DAP acquisition, followed by matching of those crowns from the different observations. Yu et al. [67] generated two ALSderived CHMs from 1998 and 2000. Individual trees were detected on both using a local maxima filter and their crowns were delineated using a watershed segmentation algorithm. The authors then used differences in tree heights derived with ALS to characterize ALS-based height growth at a plot and stand level. Authors explain that because of slow growth, short-time intervals between the point cloud acquisition, and the likelihood that the laser hits often miss the treetop, it is 
extremely difficult to estimate height growth at the individual tree level and results needed to be aggregated. With these findings however, individual tree detection was shown to be the most accurate approaches for characterizing change in top height at the plot level [77]. Some studies have attempted to address this lack of consistency in identifying individual tree crowns by using different approaches to link data from different acquisitions. For example, Yu et al. [68] built upon these findings and presented a method for estimating individual tree height growth in a Scots pine stand using two ALS acquisitions and three different techniques to estimate growth: differencing canopy models (CHMs or DSMs), comparing canopy profiles, and analyzing the difference between height histograms. Results indicated that estimated growth in height using the difference in highest ALS points inside the delineated crowns was the most accurate $\left(R^{2}\right.$ value of 0.68 and RMSE of $0.43 \mathrm{~m}$ ).

While most studies have several years between acquisitions (Fig. 3), some studies have also looked at within-year changes. The study by Dempewolf et al. [72] provides an example of within-season height growth assessment. Authors used four separate DAP datasets acquired between May and November using RPAS and quantified $\Delta \mathrm{H}$ over a 2 -ha mixed forest site. The results agreed well with published field observations, though no accuracy assessments were provided.

An important step when quantifying changes in tree attributes is tree-to-tree matching. Treetops and/or tree crowns identified at each time step need to be matched with each other in order to assess change. For example, a relatively straightforward method of tree-to-tree matching was used by Duncanson and Dubayah [24] where tree crown centroids from $\mathrm{T} 1$ were overlaid on top of T2 crowns. Tree T2 crown IDs were then transferred to T1 centroid. As the authors point out, this approach works only where there is a one-to-one match and can be problematic when crown delineations differ between the time steps. Marinelli et al. [75] used a point cloud registration algorithm to align the $\mathrm{T} 1$ and $\mathrm{T} 2$ point clouds before performing tree detection and delineation. In $\mathrm{Yu}$ et al. $[67,68]$, an automatic tree-to-tree matching algorithm was used. Trees detected at each point in time were matched based on the 2D [67] or 3D distance [68] between each other. $\mathrm{Yu}$ et al. [67] considered the trees as matching if the location of the delineated tree crowns from each point in time was within $0.5 \mathrm{~m}$. Yu et al. [68] tested two additional tree-to-tree matching techniques in which tree height and DBH were used to minimize distances between treetops. Results found that the match rate varied between 51.7 and $60.8 \%$, with the technique based on $\mathrm{X}$ and $\mathrm{Y}$ coordinates only, providing highest matching rate. Zhao et al. [53] applied a similar method incorporating planimetric distance between two treetops as well as height difference of the detected trees. The height difference component in the distance metric included a weight of 0.5 . As a second step, a manual check was performed to remove mismatched trees or trees that showed large decrease in height due to mortality or logging.

\section{Forecasting Forest Inventory Attributes}

\section{Modeling Forest Productivity with Multi-temporal Point Cloud Data}

Forest productivity is among the most important stand attributes for forest management and is crucial for characterizing stand growth. The most common way of describing forest productivity is using site index (SI), which is defined as the average height of dominant trees at a given index age [78]. Site index is a proxy for disparate information regarding climatic, edaphic, and topographic factors and was historically assigned manually by experienced field foresters familiar with the stand conditions and historical yields. Estimates of SI are used to represent anticipated future growth based on past observations and conditions, an assumption which is less reliable due to the changing climate. Despite growing misgivings in the SI concept, the prospect of being able to measure and monitor forest stands through time using spatially explicit structural data offers an objective method of characterizing stand height growth, while also providing a means of estimating change in other stand attributes (e.g., basal area) using growth simulators. Because of the capability of multitemporal point cloud data to accurately estimate changes in canopy height through time, estimation of SI is also possible. Existing studies demonstrate a number of approaches to either calibrate existing models or develop new SI models using a chronosequence of stand heights derived from a single ALS acquisition, bi-, or multi-temporal point cloud datasets.

Véga and St-Onge [79] presented the first attempt to develop a forest productivity model and map SI based on point cloud data. They used a time series of four CHMs derived from scanned historical black and white aerial photos and ALS data to develop an SI model at a $20-\mathrm{m}$ resolution. The combination of historical data acquired in 1945, 1965, and 1983, along with ALS acquired in 2003, facilitated creation of an SI model with an RMSE of $2.41 \mathrm{~m}$ and bias of $0.76 \mathrm{~m}$. The results of this study indicated that the accuracy of SI estimates increased with the number of CHM-derived height estimates used to develop the model and the time difference between acquisitions - models developed with only two CHMs with a limited time interval increased RMSE by up to $66 \%$ compared to the model developed with all four available CHMs.

SI model can also be constructed using a single ALS dataset. In such situations, a chronosequence of top heights is built by combining point cloud data with auxiliary information on stand age. In most studies, including Holopainen et al. [80], Packalén et al. [81], and Chen and Zhu [82], stand-level inventory data were used as a source of stand age. Holopainen 
et al. [80] performed an ALS-based estimation of forest productivity site types with an overall accuracy of $70.9 \%$. Packalén et al. [81] developed a site index model for eucalyptus plantations with the index age of 7 years, using the Chapman-Richards equation. The relative RMSE of the developed model was $2.8 \%$.

Alternatively, stand age may be extracted from a time series of remote sensing imagery. Tompalski et al. [22] combined ALS-based top height estimates with time since disturbance extracted from Landsat time series as a proxy of stand age. The authors then developed a species-independent site index model that overestimated site productivity by $0.7 \mathrm{~m}$ and had an RMSE of $5.55 \mathrm{~m}$. Due to the length of Landsat time series available (28 years), the site index model was developed for young stands only. A similar approach was later demonstrated by Gopalakrishnan et al. [83] who generated site index maps for loblolly pine forest by also combining ALS data with Landsat time series.

Numerous recent studies have demonstrated that canopy height growth depicted by bitemporal ALS data enables the estimation of forest productivity. Compared to methods that used a single acquisition only, growth can be extracted for the same location directly, instead of reconstructed from multiple disconnected cells. For example, Socha et al. [84] used ALS data collected in 2007 and 2012 to derive height growth trajectories and develop site index models for Norway spruce and data from 2007 and 2015 to develop site index model for Scots pine [77]. A generalized algebraic difference approach (GADA, [85]) was applied, allowing for the development of site index models that are invariant to index age, have variable asymptotes for different sites, and are characterized with polymorphism, allowing description of differences in growth patterns due to differences in site conditions.

Research has also focused on the methodological development of such models with Socha et al. [77] assessing the effect of varying height percentiles and grid cell sizes on the trajectory of growth models developed from bitemporal ALS data. Results indicated that top height growth was underestimated using the 95th or 99th percentiles of ALS point cloud heights and the degree to which this occurred was a function of stand density and silvicultural treatment. Individual tree-based assessments of top height growth were less impacted when assessed using ABA and maximum height (100th percentile) from the point cloud and were consistently better for estimating growth.

Noordermeer et al. [86] presented two methods of predicting SI at the plot level. In the direct approach, they modeled SI using bitemporal canopy height metrics, while for the indirect method, SI was predicted based on top height at $\mathrm{T} 1\left(\mathrm{H}_{\mathrm{TOP}, \mathrm{T} 1}\right)$, change in top height $\left(\Delta \mathrm{H}_{\mathrm{TOP}}\right)$, and the length of time between observations. They showed that the direct method provided slightly more accurate results for estimating SI with an RMSE of $1.78 \mathrm{~m}$ and $1.08 \mathrm{~m}$ for Norway spruce- and Scots pine-dominated stands, respectively. In a similar environment, Bollandsås et al. [87] predicted SI with an RMSE of $3.0 \mathrm{~m}$ and $2.3 \mathrm{~m}$ for spruce- and pine-dominated stands, using two sets of ALS point clouds acquired over an 11-year period. Noordermeer et al. [88] demonstrated a largescale, operational example, of predicting SI using repeated ALS data. They show the importance of including only undisturbed areas to estimate SI and classify the disturbed and undisturbed area using $\mathrm{kNN}$ with bitemporal metrics as independent variables. The \%RMSE for the predicted SI ranged between 9.83 and $20.03 \%$.

To mimic the method of determining the $\mathrm{H}_{\mathrm{TOP}}$ in the field, Kandare et al. [89] identified four dominant trees per plot $\left(400 \mathrm{~m}^{2}\right)$ using an individual tree detection approach integrated with ALS and hyperspectral data. Compared to other studies, authors aimed to develop a fully remote sensing-based method, independent of inventory data. They tested different combinations of input tree-level attributes for SI predictions, which included $\mathrm{DBH}, \mathrm{H}_{\mathrm{TOP}}$, species, and age. By alternating between field- and ALS-derived input attributes, they characterized how the accuracy of SI predictions changed. While the accuracy was similar when field- or remote sensing-derived species were used, there was a large decrease in accuracy when modeled age was used (\%RMSE: 27.6 and 7.6\%). Rather than using $\mathrm{H}_{\mathrm{TOP}}$ and age to calculate SI, the height growth model can be transformed and based on $\mathrm{H}_{\mathrm{TOP}}$ and $\Delta \mathrm{H}_{\mathrm{TOP}}$.

Wulder et al. [90] likewise compared site index estimates from an existing forest inventory to estimates generated from ALS data. To mimic the operational definition of top height used in the study area, the authors applied a $10 \mathrm{~m}$ by $10 \mathrm{~m}$ grid to the forest stands and calculated the weighted average of the maximum ALS height within each 0.01-ha grid cell within the stand using the number of non-ground ALS returns within each grid cell as weights. SI values were classified into 5-m classes to enable their use in a carbon accounting model. The ALS-derived site class was greater than the forest inventory site class for $42 \%$ of stands; however, the majority of stands (77\%) ALS site class were within \pm 1 site class of the inventory site class. Estimates of site index can then be used to inform other aspects of stand condition such as herbaceous plant species diversity and site type [91, 92].

An age-independent approach was presented by Solberg et al. [93], which transformed the existing SI models for spruce-dominated stands in Norway and applied bitemporal ALS data to calculate SI. Existing model formulas were transformed to replace the age component with the number of years between $\mathrm{H}_{\mathrm{TOP}}$ estimates derived using each of the ALS datasets. The SI estimates were strongly correlated with the reference data, with correlation coefficient $R$ equal to 0.87 and mean difference of $0.27 \mathrm{~m}$. Such transformations that substitute number of years between observations for age would of course be highly dependent upon the age and complexity of 
the forest stand. Such approaches would be more difficult to implement in natural stands with multiple species and/or high level of mortality and in areas with a larger variability of site conditions and stand age.

\section{Integrating Point Cloud Data with Growth Simulators}

Existing forest inventories can be updated by projecting current stand attributes into the future using growth simulators. Growth simulators are sets of models that describe forest stand dynamics (also called growth and yield models) and allow for the projection of individual tree or forest stand attributes to a future point in time. These simulators are the result of longterm growth monitoring programs that establish permanent plots for the purpose of monitoring forest growth. The type and number of input attributes required by a growth simulator depends on the type of model. Whole-stand growth models require less detailed information than single-tree or size-class models [94]. In most cases, the required set of input variables includes species composition, age, height, or alternatively site index. Depending on the model, additional attributes like stem density, basal area, stocking, canopy cover, and fertilization or insect damage can improve the accuracy of the estimated projections. Growth simulator outputs include the projected stand attributes, height, basal area, and volume, at a specified projection year or specified age sequence.

Integrating existing growth simulators with point cloudbased forest attribute predictions is a natural and necessary step forward from ALS-based inventories, allowing for increasing spatial detail (individual tree, cell) in growth projections. However, because existing growth simulators are designed to be integrated with the polygon-based forest inventory, their integration with point cloud-based forest attribute predictions at the grid cell (ABA) or individual tree level (ITA) is not straightforward. In recent years, there have been several studies that provide different solutions as to how the static ALS-based cell-level predictions can be projected into the future. Similar to studies focused on SI, approaches differ in the point cloud data used (single or multiple acquisitions), modeling approaches, and methods used to integrate the point cloud-based estimates with growth simulators.

In the most basic scenario, point cloud-based predictions of forest attributes can be used as the input parameters for the growth simulator (Fig. 4a). For example, Falkowski et al. [95] demonstrated how ALS-derived tree-level forest inventory data can be used to parameterize forest growth simulators. Using a tree-level Forest Vegetation Simulator, they projected BA in 10-year increments at a 20-m cell level. The results of the growth projection were compared to projections derived using forest inventory data which indicated the two estimates of BA were correlated $(R>0.91)$ and had a low RMSD $(<$ $6.5 \mathrm{~m}^{2} / \mathrm{ha}$ ). Mohamedou et al. [96] used ALS-derived topographic wetness index (TWI) and LAI estimates to improve the predictions of a national single-tree diameter growth model. By including the ALS-derived variables, RMSE was reduced from 0.60 to $0.40 \mathrm{~cm}$. Härkönen et al. [97] used a process-based model parametrized with ALS-derived input variables to calculate change in basal area. Their ALSparametrized model had an $R^{2}$ of 0.34 , which was markedly higher than when the field plot measurements were used as inputs $\left(R^{2}=0.18\right)$.

Lamb et al. [98] used a tree-list growth model to forecast forest inventory at a grid cell level in spruce plantations. A library of candidate tree lists was first compiled using over 65,000 ancillary forest inventory plots collected in spruce plantations in New Brunswick, Canada. Tree lists and ALS were not required to be temporally close with their empirical measurement. Tree lists were partitioned by species composition and stand type and were assigned to every $20-\mathrm{m}$ cell based on the smallest difference (Euclidian distance) between six inventory attributes predicted with ALS and measured on plots. Assigned tree lists were then used as input for the growth model (Fig. 4b). To assess the accuracy, authors used a separate set of 98 calibration plots and compared the annual increments derived using tree lists imputed by plot matching and tree lists measured in the field. Results showed a strong agreement (Pearson's R between 0.75 and 0.86 ) between the increments, with relative RMSE between 12.8 and 49\%.

An important component of the tree-list approach was the integration of independent unbiased forest inventory ground plots (systematic or random continuous forest inventory) to correct forest-level bias in ALS metrics and forest-level species composition interpretation bias for purposes of accurate timber supply modeling. In comparison to the continuous forest inventory plots, the imputed ALS-plot-matched forest inventory overestimated total volume by $4 \%$, and species-level volume bias was also evident, especially for incidental species. Total volume bias resulted from ALS volume bias, and species volume bias resulted because stand-level photointerpreted species proportions were either slightly biased for common species or were greatly underestimated for incidental species that are not explicitly reported in the photointerpreted stand attributes, e.g., small patches of residual white pine in a regenerating spruce-fir stand. As remotely sensed ABA species predictions become more reliable, these estimates will likely replace photointerpreted species proportions during plot matching. In general, with a sufficiently large plot library covering nearly all forest conditions, plot matching will closely "match" the same level of accuracy as ALS and species interpretation at stand and forest levels, so as these two key inputs improve, so will the imputed plotmatched forest inventory accuracy.

In the approach presented by Tompalski et al. [99, 100], a database of growth trajectories was first created using an existing growth simulator and a range of required input parameters including species, age, and SI. Growth curves were 
a Parametrizing a growth simulator

Point cloud-derived

input parameters
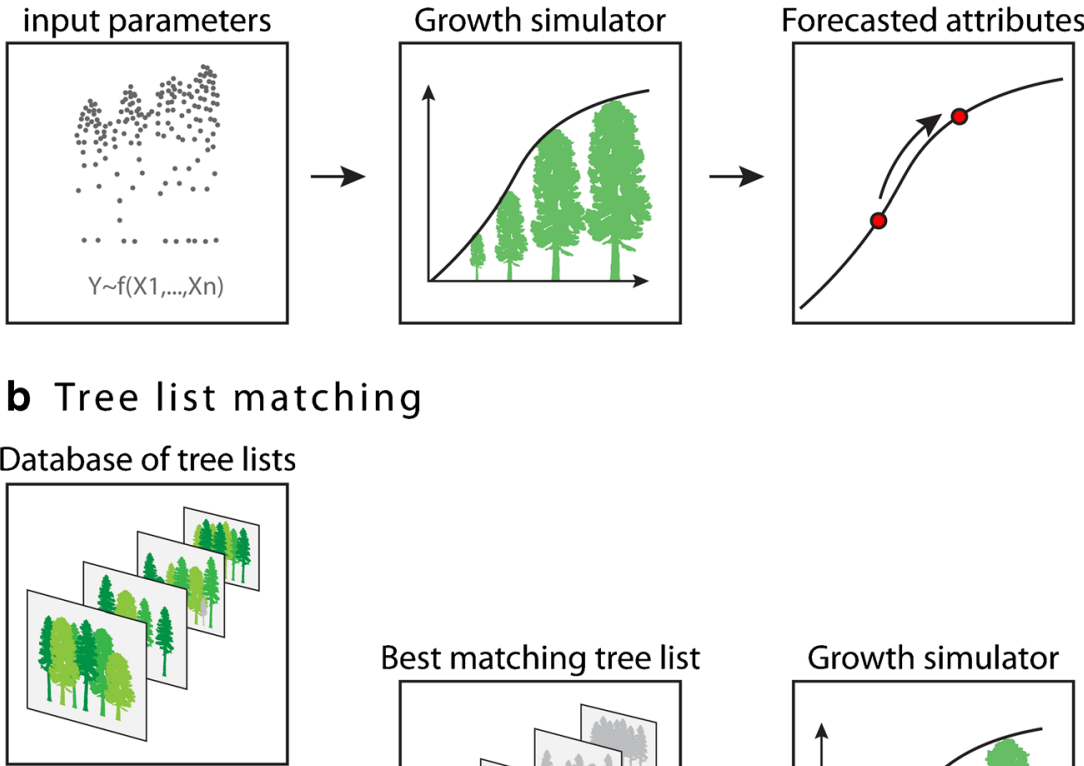

\section{b Tree list matching}

\section{Database of tree lists}
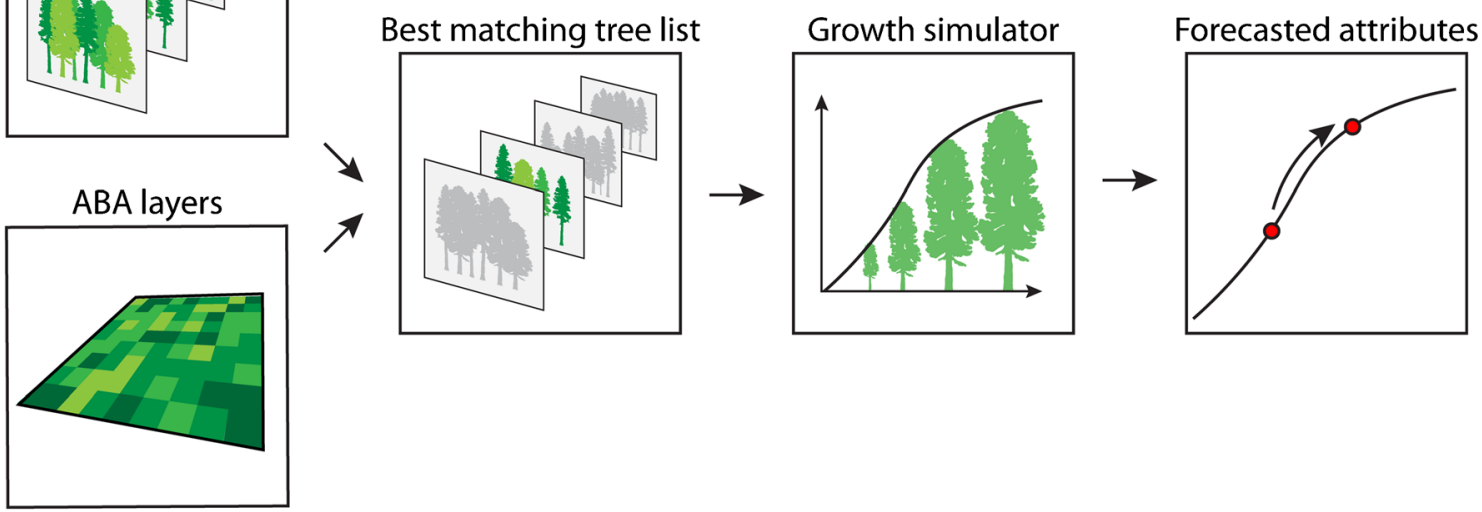

\section{c Curve matching}

\section{Growth simulator}
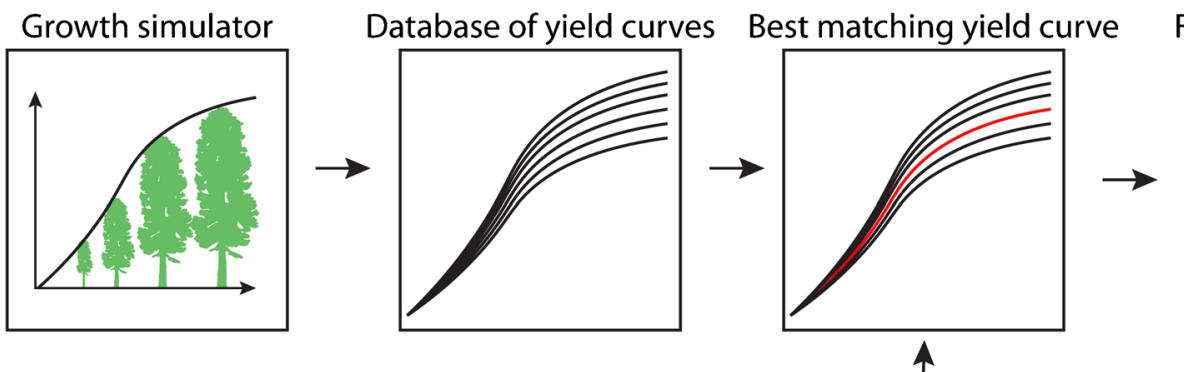

Forecasted attributes

ABA layers

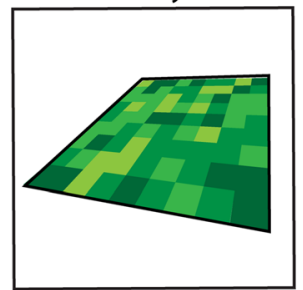

Fig. 4 Approaches to integrate growth simulators with point cloud data to forecast forest inventory attributes. ABA, area-based approach

then assigned to every 20 -m cell based on the minimum difference between ALS-derived inventory attributes (Fig. 4c). Specifically, candidate curves were first identified based on dominant species and stand age, and a further selection was made based on the smallest difference between attribute values estimated with ALS and defined by each of the curves. 
Because multiple stand attributes may be used, the final growth curve is selected using a weighted mean of residuals, with the accuracy of the estimated attributes used as weight. This method was used with a single ALS acquisition and the TIPSY growth simulator [101] in coastal temperate rainforest in British Columbia, Canada [99] and with bitemporal point cloud dataset and GYPSY growth simulator [102] in pine- and spruce-dominated boreal forests in Alberta [100].

The specific method of integrating growth simulators with ALS-based estimates of forest attributes depends mostly on the growth simulator itself. The major categories of growth simulators, tree- or stand-based, determine the required suite of input parameters and their level of detail. The stand-level growth simulators are the simplest; however, they are insufficient when information on size class or individual trees is required. Individual tree-level simulators are the most complex and detailed, with individual trees used as the basic unit for modeling. The growth curve matching approach described by Tompalski et al. $[99,100]$ was designed to work with stand-level growth models, which are currently used in operational forestry in British Columbia and Alberta, Canada. In the approaches presented by Falkowski et al. [95] and Lamb et al. [98], tree-level growth simulators were used, and the approaches were designed to find a tree list for each cell that would result in the most accurate growth projections. A treelevel growth simulator was also used by Marczak et al. [103] who performed a sensitivity analysis and tested different combinations of input parameters derived from ALS or traditional inventory in mixed temperate forest stands in Ontario, Canada. Four different scenarios were tested with the growth simulator parametrized with either inventory data only (baseline scenario) or different combinations of ALS-derived tree lists and inventory or photointerpreted species abundance. The results indicated that neither of the ALS-based projections were equivalent to the inventory-initialized baseline, which authors attribute to poor predictions of stem size distribution, stem density, and basal area distribution.

\section{Data Assimilation}

Data assimilation is a mathematical procedure to update existing estimates with new observations. In a forest inventory context, data assimilation can be used to combine the existing estimates of forest attributes, with new information derived based on new acquisitions [104]. Therefore, existing forest inventory information is not discarded when new data is acquired but instead integrated into the modeling framework. In essence, existing information on forest attributes are first forecasted into the future using a model that, in addition to the forecasted estimates, provides information on the uncertainty of that estimate. In the second step, the forecasted information is compared to that derived from the new acquisition. Because the uncertainties are known, when the two pieces of information are combined, the weights are used that are inversely proportional to their uncertainties $[105,106]$. The existing studies show that the data assimilation approach may lead to an increase of the prediction accuracy by 10 $74 \%$ [107]. In the context of this review, it is important to note that although data assimilation approaches contain a forecasting part, the forecasting is performed to improve the accuracy of the current estimates.

Data assimilation approaches are applied in a multitude of domains and, due to application-specific issues, need to be parametrized for each application. In forest inventory, those issues include data type, resolution, and modeling approaches [108]. The adaptation of data assimilation for forest inventory involves the development of new growth models that do not only allow predictions of growth but also inform on the uncertainty of growth predictions [105]. For example, [105, 108] developed nonlinear models to forecast stand attributes. The growth function was based on a regression model derived from a network of permanent sample plots.

Two general data assimilation techniques are available. The first technique utilizes a Kalman filter, which is an optimal estimation algorithm [109]; the second is based on Bayesian statistics. Kalman filtering requires an assumption that the errors of both the forecasted value and errors of the new estimates are normally distributed, while Bayesian methods are more flexible and can be used with any distributions. An extended Kalman filter can be used if nonlinear prediction models are required [108].

An example of data assimilation applied in forest inventories can be found in Nyström et al. [105]. In their study, they aimed to estimate forest attributes in 2011 by combining point cloud-based estimates acquired between 2003 and 2011 (six DAP datasets) with estimates of those attributes from the developed growth models. First, an ABA was used to estimate $\mathrm{H}, \mathrm{BA}$, and $\mathrm{V}$, for each acquisition using a corresponding set of training plots. Linear regression was used to predict $\mathrm{H}$, and nonlinear regression was used to predict BA and V. Because data assimilation requires the error variance estimates and because the residual variance in the case of the nonlinear models was not constant, authors developed linear models to predict residual standard deviation. Using a separate set of permanent sample plots, growth models were developed for each of the three stand attributes. In the next stage, the extended Kalman filter was used to model the stand attributes over time. At each time step, and for every cell, the growth model was used to forecast the attribute value (forecasting step), which was then adjusted using the point cloud-based prediction (assimilation step). The contribution of each variable in the assimilation step is inversely proportional to their variances. By comparing the accuracy of the stand attributes estimated using data assimilation, forecasting with the growth models, and the most recent estimate, authors showed that the assimilated estimate had the lowest \%RMSE. 
Data assimilation has great potential to reduce the uncertainty in forest attribute estimates when multiple remote sensing datasets are available [104]. However, because specific requirements regarding the growth component are essential, specifically that the estimated uncertainty of the forecasted attributes is known, the application of data assimilation may be challenging. The growth models used by $[105,108]$ were constructed to predict 5-year increments of $\mathrm{H}, \mathrm{BA}$, and $\mathrm{V}$ using a network of plot data remeasured three to four times. Compared to traditional growth simulators used in forestry, those models were simplified and did not include, for example, ingrowth or mortality. However, those simplified models are an example that, for short forecasting scenarios, sophisticated growth simulators are not always necessary, especially when they are used to update forest inventories.

\section{Challenges in Estimating Growth with Point Cloud Data}

As demonstrated throughout, studies have found that both ALS and DAP point cloud datasets are capable of being used for forest attribute growth analysis. While the vast majority of studies used ALS data acquired at each time step, in several cases, ALS and DAP data were integrated. Datasets of different types, point densities, scan angles, and sensors were present in all studies and, while this introduced an additional challenge, did not impede the successful assessments of change. However the estimation accuracy depended on the particular attribute being estimated.

The majority of existing studies that utilized multitemporal point cloud data incorporated just two ALS datasets (over 95\% of all reported studies). Data were often acquired with different sensors, point densities, and at different seasonal dates. However, as Zhao et al. [53] demonstrated in sprucedominated stands in Scotland, datasets with different densities can be used, and, in case of tree-level analysis, if the density exceeds 7 points $/ \mathrm{m}^{2}$, no decrease in accuracy was observed. At a cell level, Cao et al. [50] found that differences in point density did not affect the accuracy of the developed models. Although variations in ALS sensor characteristics and acquisition parameters may have an impact on the estimation of forest growth, in an area-based context, the spatial distribution of the point cloud is similar even if the point density varies markedly and increasing point density does not increase areabased estimation accuracy [36, 110]. This finding is crucial as modern ALS datasets are often collected with point densities that are an order of magnitude higher than a decade ago. In the majority of the reviewed studies, the point density was greater for each subsequent acquisition (Fig. 3). The ability to combine sparse historical ALS point clouds with denser datasets acquired using modern instruments (including single-photon lidar) to characterize stand growth is an important consideration for EFIs. However, as described by Roussel et al. [111], point density influences the CHM, with denser point clouds resulting in higher elevation values of the $\mathrm{CHM}$ pixels. Therefore, if the multi-temporal point cloud-based analysis uses a CHM, a correction needs to be introduced to avoid bias in the change estimates. At the individual tree level, Duncanson and Dubayah [24] used point clouds acquired with two different sensors operating with different wavelengths, densities, scan angles, and side overlap. To minimize potential issues with change detection, data from each acquisition was filtered to a maximum scan angle of $15^{\circ}$. Application of such a filter is especially important in individual tree-based approaches as it may reduce differences in crown shapes associated with wide scan angles and resulting occlusions.

Several authors demonstrated how multi-temporal analysis can be performed by combining ALS and DAP point clouds [e.g., 31, 32, 69]. In such scenarios, the ground elevation is extracted from the $\mathrm{ALS}_{\mathrm{T} 1}$ acquisition and used to normalize both $\mathrm{ALS}_{\mathrm{T} 1}$ and $\mathrm{DAP}_{\mathrm{T} 2}$ data $[8,59]$. The typical lack of ground returns under forest canopy characteristic for DAP is therefore overcome and a suite of point cloud structural metrics can be derived from both point clouds. Integration of ALS and DAP datasets facilitates a multi-temporal analysis of forest attributes at markedly lower cost and can be used to update large-scale forest inventories [8]. Further, as demonstrated by Véga et al. [79], some historical aerial photography can be processed to provide baselines and/or retrospective assessments of stand growth as well. The quality of image matching is however critical for accurate reconstruction of forest canopy [112]. As the technology progresses and the image matching algorithms become more advanced [113], the derived DAP point clouds better represent the 3D structure of the forest stand.

Regardless of the method used to characterize change, the datasets used must be co-registered, with even marginal spatial mismatches contributing to large errors in change assessment, especially at the tree level [75]. Point cloud co-registration is important for all data types but can be especially challenging when integrating ALS and DAP data due to the differences in point cloud structure or often lower geo-referencing accuracy in case of $\mathrm{DAP}_{\mathrm{RPAS}}$. Co-registration may be especially challenging when historical data is used, such as DAP point clouds derived from archival panchromatic images [79, 114].

Estimates of change at the individual tree level, although more detailed, are prone to errors originating from the detection method itself as well as tree-to-tree matching [25, 68]. Because tree segmentation results may differ for each time step, a tree-to-tree matching algorithm to automatically match the detected trees is used. In most cases, such algorithms match trees based on the distance between treetops and difference in height $[67,68]$. To improve the overall accuracy of change estimates, errors in tree-to-tree matching may be corrected manually [53] or by excluding tree segments with multiple matches or large distance between treetops [74]. 
Many of the challenges associated with estimating change in stand attributes using 3D point clouds correspond to challenges when a single dataset is used to estimate those attributes at a single point in time. For example, the temporal misalignment between field measurements and remotely sensed data that occurs when the response variable and point cloud metrics are measured at different times can lead to erroneous predictions [115]. In the case of multi-temporal analysis, the influence of such misalignment increases as the errors of each developed model compound. The importance of reference data cannot be neglected either-preferably, field observations need to be collected coincidentally with the point cloud data, at every time period. Estimating forest attributes in young stands is another challenge because the correlations between forest attributes and point cloud metrics are weaker and are influenced by the high stem density and species variability $[107,116]$.

The accuracy of the estimated change depends on the attribute of interest. Because point cloud metrics are strongly correlated to stand height, estimates of tree- or cell-level height, and change in height, are the most accurate. Among the summarized research, a tree- and cell-level change in height was always the most accurately estimated attribute compared to other tree or stand attributes (Table 1). Despite the fact that changes in height are most accurately determined, the use of different height measures may result in different change values $[33,77]$.

For ITA, height growth has been most accurately estimated by using the difference in the highest ALS points within delineated tree crowns [68]. Application of height estimates from ALS and DAP data as inputs to growth models requires unification to stand heights defined when calibrating the model growth functions. When determining the height of trees using laser scanning, it may be possible to measure the height of dead trees, which can be an additional reason for underestimation of the change in height $[59,77]$. However, selfthinning concerns mainly suppressed trees and therefore, dead trees are not often the highest trees within subplots. The height of dead trees is therefore taken into account more often when the height of the plot/stand is calculated as the 95th or 99th percentile of the point cloud. The use $\mathrm{H}_{\mathrm{TOP}}$ defined as the mean maximum height from 0.01-ha subplots obtained by ITA or 100th percentile may additionally limit the likelihood of calculation of $\mathrm{H}_{\mathrm{TOP}}$ and $\Delta \mathrm{H}_{\mathrm{TOP}}$ using heights of dead trees.

Other attributes like $\Delta \mathrm{BA}, \Delta \mathrm{V}$, or $\Delta \mathrm{AGB}$ often had accuracy more than two times lower compared to estimates of $\Delta \mathrm{H}$, at both tree and cell level. Several authors have investigated how various factors influence the accuracy of change estimates. For example, Hopkinson et al. [33] showed that the uncertainty of height growth estimated at the cell level depends on the repeat interval between data acquisitions. In their study conducted in a red pine-dominated plantation, they showed that if a $10 \%$ uncertainty is considered acceptable, a
3 -year time interval is required between acquisitions in order to ensure that growth exceeds the level of uncertainty in the estimate. Tompalski et al. [59] demonstrated that stand mortality has an effect on the accuracy of change estimates. They performed a sensitivity analysis and developed predictive models based on reference data with different levels of mortality. The results showed that a mortality level of about $20 \%$ corresponded to a $200 \%$ increase in $\%$ RMSE for $\Delta \mathrm{V}$. In both cases, results are influenced by forest conditions and growth rates. Results for even-aged, single species plantations are applicable in similar forest environments.

In slow-growing stands, or if the repeat interval between data acquisitions is short, the uncertainty of change estimates can be higher than the estimated change in the stand growth. Under these circumstances, additional attention is required because estimated growth may not be reliable for some or all attributes. For example, in slow-growing stands, if the annual increment in $\mathrm{H}$ and $\mathrm{V}$ is $0.12 \mathrm{~m} / \mathrm{year}$ and $1.97 \mathrm{~m}^{3} / \mathrm{ha} / \mathrm{year}$, respectively, while the errors in $\Delta \mathrm{H}$ and $\Delta \mathrm{V}$ are $1.71 \mathrm{~m}$ and $47.8 \mathrm{~m}^{3}$, the repeat interval needs to be equal to at least 14 and 24 years, respectively, in order to provide reliable estimates of growth in $\mathrm{H}$ and V [59]. In contrast, Dempewolf et al. [72] showed that within-season assessment of height growth at the tree level can be performed using DAP data acquired from RPAS.

Challenges related to forecasting forest attributes with point cloud-based estimates go beyond considerations related to the data, acquisition time, or approach. Because each of the described approaches to forecast inventory attributes differs, the specific challenges differ as well. Multiple examples of studies that used multi-temporal point cloud data to estimate or model site index, or integrated point cloud-based estimates with growth models, show the importance of stand age estimates. In the majority of studies, existing inventory data is used as a source of stand age; however, as demonstrated by Holopainen et al. [80], errors of 5 years in stand age dramatically influence the predicted site productivity. Errors in stand age lead to a reduction in accuracy of the SI estimates or growth projections [117], and the overall effect of error in age is larger than the error in $\mathrm{H}_{\mathrm{TOP}}$, especially in unmanaged stands or stands of complex structure.

To demonstrate and compare the effect of error in height and age on the SI estimates, we simulated how the height-age curve will change depending on different error levels. To do this, we used an existing SI model [84] and calculated $\mathrm{H}_{\text {TOP }}$ values between 20 and 120 years, with a SI value of 20 . We then altered the input parameters, modifying $\mathrm{H}_{\mathrm{TOP}}$ by 1,2 , and $5 \mathrm{~m}$ and modifying age by 5,10 , and 20 years. The result shown on Fig. 5 reveals how the error introduced to both variables affects the calculated $\mathrm{H}_{\text {TOP. }}$. While the accuracy of point cloud-based estimates of $\mathrm{H}$ is typically better than $2 \mathrm{~m}$, error in age at a stand level can exceed 10 or even 20 years in some cases, especially when stand age is assessed using image interpretation. 
Fig. 5 Age-height curve and its variability resulting from errors in height (left panel) and age (right panel). Age-height curve was derived with site index model presented by [84], with a SI value of 20 . We simulated the errors in height to be 1,2 , or $5 \mathrm{~m}$, and the errors in age to be 5,10 , or 20 years

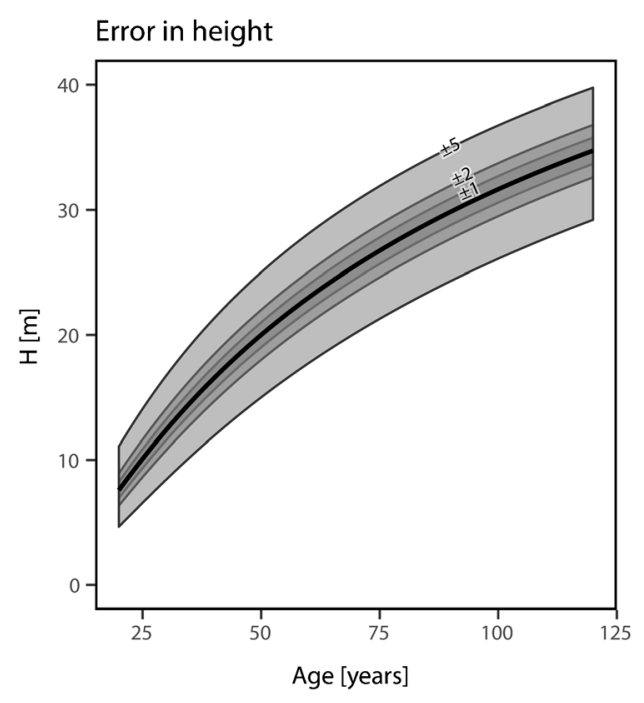

To improve the accuracy of point cloud-based forecasts of stand attributes, all of the required variables, including age and species composition, should be available at the same level of detail, which in all of the existing examples is a raster cell. However, accurate estimates of species at the individual tree level or of dominant species at the raster cell level derived from three-dimensional point data alone remain challenging. Research using remote sensing to improve estimates of age $[114,118,119]$ and estimate species composition $[120,121]$ is ongoing and is demonstrating the potential to generate wallto-wall raster layers of both attributes. For younger stands, stand age can be derived from time series of satellite imagery when stand records are not available [22, 122-124]. The required degree of accuracy of these estimates however depends on how these outputs are used in operational decision making with ongoing research still required on the trade-offs between individual species accuracy and broader applications.

Alternatively, approaches that are age- or species- independent can be developed. The approach presented by Solberg et al. [93] is especially important and relevant for the ongoing research on estimating stand productivity with time series of point cloud data. Removing the age component, and substituting it with the change in $\mathrm{H}_{\mathrm{TOP}}$ in order to estimate $\mathrm{SI}$, makes this approach especially suitable to use with bitemporal point cloud data. As shown by Kandare et al. [89], inaccurate predictions of age can increase the \%RMSE of SI predictions by almost fourfold (from 7.6 to $27.6 \%$ ).

\section{Research Gaps and Recommendations}

While the existing research provides multiple examples of how multi-temporal point cloud data can be used to characterize forest growth, there remain a multitude of scientific justifications to continue research on this topic. The existing approaches are not yet ready for operationalization, and questions on specific methods to use with different data types, the number of different datasets available, or the optimal time interval between data acquisitions, among others, remain. Underpinning our recommendations is a need for statistical rigor when analyzing multi-temporal point clouds. For example, a selected modeling approach needs to be able to produce both negative and positive results and extra caution must be paid when using the model to extrapolate beyond the original range of change captured in the training data [30].

From our review of the literature, several research gaps emerged:

\section{Guidance on When to Apply Direct or Indirect Approaches} More research is needed to better inform which approach is preferable given a certain set of forest conditions and available datasets. While the majority of existing research shows that the direct approach is more accurate, several publications demonstrated the opposite. As multi-temporal three-dimensional datasets become more prevalent, we recommend the opportunity be exploited to test both direct and indirect approaches where possible to provide more consistent recommendations of which approach to use where and why. Furthermore, the increased availability of 3D data will also allow to examine wider range of attributes, varying time spans between data acquisitions, range of species compositions, and growth rates of the forest stand.

Improving Tree-to-Tree Matching Over Time At the individual tree level, additional research is required to improve the performance and consistency of tree detection methods [125], develop tree detection methods using multi-temporal point clouds simultaneously as inputs, and improve tree-to-tree matching. Given the large number of ITAs and methods available, we are reluctant to recommend the development of yet more individual tree detection methods; however, we recognize that the availability of multi-temporal $3 \mathrm{D}$ data provides a 
unique opportunity for ITA methods development. It is logical to assume that the estimation of deciduous versus coniferous tree species would be immediately improved if multi-seasonal data were used simultaneously, and when integrated over time, growth assessments could be estimated concurrently. To extend the suite of tree-level growth estimates, research should also focus on characterizing change not only in tree height but also other attributes.

Multi-temporal Growth Analysis The majority of studies we reviewed used bitemporal point cloud data and developed approaches to best assess or forecast the change in forest attributes. Additional research is required to identify best approaches to estimate forest growth when more than two datasets are available. As ALS acquisition becomes more common, the availability of multiple ALS datasets for a given forest management unit will increase. Approaches are required to enable the use of these data to track forest growth over time. For example, if point clouds (both ALS and DAP) are acquired on a regular cycle (e.g., every 3 years), is the direct or indirect approach the preferred method for estimating change, or can alternative methods be developed that would take advantage of the trajectories of forest attributes extracted for each cell or tree crown?

\section{Integration of Point Cloud Data into Existing Growth Models}

Research is required to identify the best approaches to integrate point cloud data into growth simulators. As shown, existing methods are in the early stages of development and are often specifically designed to work with an existing growth simulator or for a particular forested region. Research should focus on leveraging point cloud information to better parametrize existing growth simulators, for example, by improving estimates of SI or similar attributes that diminishes the reliance upon a photointerpreted or point cloud predicted age. Given improved estimates of these initial stand conditions, provided by point cloud data, existing growth models can then be applied to predict future yield. A key benefit of developing robust and flexible linkages with existing growth simulators is the ability to make predictions over longer time horizons (decades into the future) for strategic planning where 100-year forecasts are commonly needed. In addition, these existing modeling approaches are often integrated into forest management scenarios such as silvicultural treatments over time, as well as being used to assess impacts of pests and disease. When estimating key forest attributes over time, the effect of raster cell size, and point cloud metric selection is also important to consider.

Estimates of Age and Species Both stand age and species composition can influence the accuracy of growth estimates through use of an incorrect stand initiation date or model selection, for instance. More research is required to identify approaches to improve stand age and species composition, including methods that integrate other remotely sensed datasets.

Growth Models Driven Entirely with Point Cloud Data Considering the cost associated with the development of growth simulators using traditional approaches, research should aim to continue to incorporate remote sensing-based products to improve estimates from growth and yield models. Examples provided by Ehlers et al. [108] and Nyström et al. [105] inform not only on the necessity of improved growth function but also demonstrate how such functions can be developed. Remote sensing-based growth functions do not necessarily need to mimic existing growth simulators that often contain complex modules to characterize mortality, ingrowth, competition, or account for various silviculture activities (e.g., thinning, fertilization) but rather utilize the advantages provided by point clouds and other remote sensing data.

\section{Summary}

There are an increasing number of published studies estimating forest growth with 3D point cloud data. These studies have employed a wide range of methods utilizing bi- or multitemporal 3D data at varying spatial resolutions. The growing availability of point cloud data (both ALS and DAP), as well as the practical need for inventory purposes to obtain accurate estimates of change in forest attributes and future projections of those attributes, are a logical step towards more accurate growth analysis at finer levels of detail. The studies examined herein demonstrate that further research is needed to improve both retrospective estimates of growth and methods to forecast forest attributes.

As shown in this review, ALS or DAP point clouds can be used to characterize forest growth in an accurate and costeffective manner over large areas. $\mathrm{Bi}$ - and multi-temporal point cloud datasets can be used to reliably characterize growth retrospectively, as well as facilitate the forecasting of stand conditions. These 3D data provide growth estimates at a much finer level of spatial detail compared to standard polygon-based inventories and polygon-based growth analysis. Based on the reviewed research from the two levels of detail, i.e., area-based and individual tree analysis, areabased analyses at the cell level are more straightforward to apply as they do not face problems related to tree-to-tree matching. Height increment is the most accurately estimated attribute for both ITA and ABA, with errors less than $0.5 \mathrm{~m}$ reported in multitude of studies; however, special attention is required in slow-growing stands, particularly when the time interval between data acquisitions is short. In such cases, the error in growth estimates can exceed the actual reported growth and lead to unreasonable conclusions. 
Multi-temporal applications of point cloud dataset can be greatly extended by integrating ALS or DAP datasets with growth simulators, which will enable stand attributes to be forecasted and will support forest planning with detailed, sub-stand projections. Estimates of age and species composition at a similar level of spatial detail are currently lacking but would further increase the accuracy of such projections, providing a suite of attributes to parametrize existing growth simulators without auxiliary, polygon-level data.

Finally, with the growing availability of point cloud data, more and more areas will be covered by two and by greater than two acquisitions - this presents a unique opportunity to improve forest growth analysis at longer time period on one hand but highlights the need for research focusing on developing robust approaches to quantify growth on the other.

Acknowledgments This research was funded by the AWARE (Assessment of Wood Attributes using Remote Sensing) Natural Sciences and Engineering Research Council of Canada Collaborative Research and Development grant to a team led by Dr. Nicholas Coops (CRDPJ 462973 - 14). We thank Sean Lamb for his comments and edits to the manuscript. We thank the editors and the anonymous reviewers for their time and insightful comments that allowed us to improve our manuscript.

Open Access This article is licensed under a Creative Commons Attribution 4.0 International License, which permits use, sharing, adaptation, distribution and reproduction in any medium or format, as long as you give appropriate credit to the original author(s) and the source, provide a link to the Creative Commons licence, and indicate if changes were made. The images or other third party material in this article are included in the article's Creative Commons licence, unless indicated otherwise in a credit line to the material. If material is not included in the article's Creative Commons licence and your intended use is not permitted by statutory regulation or exceeds the permitted use, you will need to obtain permission directly from the copyright holder. To view a copy of this licence, visit http://creativecommons.org/licenses/by/4.0/.

\section{References}

1. Fridman J, Holm S, Nilsson M, Nilsson P, Ringvall A, Ståhl G. Adapting National Forest Inventories to changing requirements the case of the Swedish National Forest Inventory at the turn of the 20th century. Silva Fenn. 2014;48. http://www.silvafennica.fi/ article/1095

2. Gillis MD, Leckie DG. Forest inventory update in Canada. For Chron. 1996;72:138-56.

3. Coops, N.C., 2015. Characterizing Forest Growth and Productivity Using Remotely Sensed Data. Current Forestry Reports 2015;1:195-205. Available from: http:// link.springer.com/10.1007/s40725-015-0020-x

4. Tompalski P, Coops NC, White JC, Wulder MA. Augmenting site index estimation with airborne laser scanning data. For Sci. 2015;61:861-73.

5. Nabuurs GJ, Mohren F, Dolman H. Monitoring and reporting carbon stocks and fluxes in Dutch forests. Biotechnol Agron Soc Environ. 2000;4:308-10.

6. Verkerk PJ, Fitzgerald JB, Datta P, Dees M, Hengeveld GM, Lindner $M$, et al. Spatial distribution of the potential forest biomass availability in Europe. For Ecosyst Forest Ecosystems. 2019;6:1-11.

7. Kurz WA, Dymond CC, White TM, Stinson G, Shaw CH, Rampley GJ, et al. CBM-CFS3: a model of carbon-dynamics in forestry and land-use change implementing IPCC standards. Ecol Model. 2009;220:480-504.

8. Goodbody TRH, Coops NC, White JC. Digital aerial photogrammetry for updating area-based forest inventories: a review of opportunities, challenges, and future directions. Curr for reports [internet]. Current Forestry Reports. 2019;5:55-75. https://doi.org/ 10.1007/s40725-019-00087-2.

9. White JC, Coops NC, Wulder MA, Vastaranta M, Hilker T, Tompalski P. Remote sensing technologies for enhancing forest inventories: a review. Can J Remote Sens. 2016;42:619-41.

10. Hawryło P, Tompalski P, Wężyk P. Area-based estimation of growing stock volume in Scots pine stands using ALS and airborne image-based point clouds. Forestry. 2017;i:1-11.

11. White JC, Wulder MA, Vastaranta M, Coops NC, Pitt D, Woods $\mathrm{M}$. The utility of image-based point clouds for forest inventory: a comparison with airborne laser scanning. Forests. 2013;4:518-36.

12. Vastaranta M, Wulder MA, White JC, Pekkarinen A, Tuominen S, Ginzler C, et al. Airborne laser scanning and digital stereo imagery measures of forest structure : comparative results and implications to forest mapping and inventory update. Can J Remote Sens. 2013;39:382-95.

13. Antonio J, Luís J, Marino E, Guillén-climent ML, Fernándezlanda A. Int J Appl earth Obs Geoinformation assessing the transferability of airborne laser scanning and digital aerial photogrammetry derived growing stock volume models. Int J Appl earth Obs Geoinf. Elsevier; 2020;91:102135.: https://doi.org/10.1016/j.jag. 2020.102135, 2020.

14. Tompalski P, White JC, Coops NC, Wulder MA. Demonstrating the transferability of forest inventory attribute models derived using airborne laser scanning data. Remote Sens environ. Elsevier. 2019;227:110-24. https://doi.org/10.1016/j.rse.2019. 04.006 .

15. White JC, Wulder MA, Varhola A, Vastaranta M, Coops NC, Cook BD, et al. A best practices guide for generating forest inventory attributes from airborne laser scanning data using an areabased approach. 2013.

16. White JC, Tompalski P, Vastaranta M, Wulder MA, Saarinen S, Stepper C, et al. A model development and application guide for generating an enhanced forest inventory using airborne laser scanning data and an area-based approach: CWFC Information Report FI-X-018, Canadian Forest Service, Pacific Forestry Centre: Victoria, BC, Canada. 38 pp; 2017.

17. Lim K, Treitz P, Wulder MA, St-Onge B, Flood M. LiDAR remote sensing of forest structure. Prog Phys Geogr. 2003;27:88106. https://doi.org/10.1191/0309133303pp360ra.

18. Wulder MA, Bater CW, Coops NC, Hilker T, White JC. The role of LiDAR in sustainable forest management. For Chron. 2008;84: 807-26. https://doi.org/10.5558/tfc84807-6.

19. Vastaranta M, Kankare V, Holopainen M, Yu X, Hyyppä J, Hyyppä H. Combination of individual tree detection and areabased approach in imputation of forest variables using airborne laser data. ISPRS J Photogramm Remote Sens. International Society for Photogrammetry and Remote Sensing, Inc. (ISPRS); 2012 [cited 2014 Mar 28];67:73-9. http://linkinghub.elsevier. com/retrieve/pii/S092427161100116X

20. Hyyppä J, Inkinen M. Detecting and estimating attributes for single trees using laser scanner. Photogramm J Finl. 1999;16:27-42.

21. Næsset E. Predicting forest stand characteristics with airborne scanning laser using a practical two-stage procedure and field data. Remote Sens Environ. 2002 [cited 2013 Nov 14];80:88-99. http:// www.sciencedirect.com/science/article/pii/S0034425701002905 
22. Tompalski P, Coops NC, White JC, Wulder MA, Pickell PD. Estimating Forest site productivity using airborne laser scanning data and Landsat time series. Can J Remote Sens. 2015;41:23245. https://doi.org/10.1080/07038992.2015.1068686.

23. Tompalski P, Coops NC, Wulder MA, Bailey T. Combining multi-date airborne laser scanning and digital aerial photogrammetric data for forest growth and yield modelling. Remote Sens. 2018;10:1-21.

24. Duncanson L, Dubayah R. Monitoring individual tree-based change with airborne lidar. Ecol Evol. 2018;8:5079-89.

25. Hyyppä J, Xiaowei Y, Rönnholm P, Kaartinen H, Hyyppä H. Factors affecting object-oriented forest growth estimates obtained using laser scanning. Photogramm J Finl. 2003;18:16-31.

26. Bohlin J, Wallerman J, Fransson JES. Forest variable estimation using photogrammetric matching of digital aerial images in combination with a high-resolution DEM. Scand J For Res. 2012;27: 692-9. https://doi.org/10.1080/02827581.2012.686625.

27. White JC, Stepper C, Tompalski P, Coops NC, Wulder MA, White JC, et al. Comparing ALS and image-based point cloud metrics and modelled forest inventory attributes in a complex coastal forest environment. Forests Multidisciplinary Digital Publishing Institute. 2015;6:3704-32.

28. Järnstedt J, Pekkarinen A, Tuominen S, Ginzler C, Holopainen M, Viitala R, et al. Forest variable estimation using a high-resolution digital surface model. ISPRS J Photogramm Remote Sens. 2012;74:78-84

29. Gobakken T, Bollandsås OM, Næsset E. Comparing biophysical forest characteristics estimated from photogrammetric matching of aerial images and airborne laser scanning data. Scand J For Res. Taylor \& Francis; 2015;30:73-86. https://doi.org/10.1080/ 02827581.2014 .961954

30. McRoberts RE, Bollandsås OM, Næsset E. Modeling and estimating change. For Appl Airborne Laser Scanning Concepts Case Stud. 2014. p. 293-313.

31. Noordermeer L, Økseter R, Ole Ørka H, Gobakken T, Næsset E, Bollandsås OM. Classifications of forest change by using bitemporal airborne laser scanner data. Remote Sens. 2019;11.

32. Næsset E, Gobakken T. Estimating forest growth using canopy metrics derived from airborne laser scanner data. Remote Sens Environ. 2005;96:453-65.

33. Hopkinson C, Chasmer L, Hall RJ. The uncertainty in conifer plantation growth prediction from multi-temporal lidar datasets. Remote Sens Environ. 2008;112:1168-80 http://www. sciencedirect.com/science/article/B6V6V-4PPFTF3-3/2/ 9a1e7a57527c379ac07830c8f678a3c3.

34. Yu X, Hyyppä J, Kaartinen H, Maltamo M, Hyyppä H. Obtaining plotwise mean height and volume growth in boreal forests using multi-temporal laser surveys and various change detection techniques. Int J Remote Sens. 2008;29:1367-86. https://doi.org/10. 1080/01431160701736356.

35. Dubayah RO, Sheldon SL, Clark DB, Hofton MA, Blair JB, Hurtt $\mathrm{GC}$, et al. Estimation of tropical forest height and biomass dynamics using lidar remote sensing at la Selva. Costa Rica J Geophys Res Biogeosciences. 2010;115:1-17.

36. Hudak AT, Strand EK, Vierling LA, Byrne JC, Eitel JUH, Martinuzzi S, et al. Quantifying aboveground forest carbon pools and fluxes from repeat LiDAR surveys. Remote Sens Environ. Elsevier B.V.; 2012;123:25-40. https://doi.org/10.1016/j.rse. 2012.02.023

37. Bollandsås OM, Gregoire TG, Næsset E, Øyen BH. Detection of biomass change in a Norwegian mountain forest area using small footprint airborne laser scanner data. Stat Methods Appl. 2013;22: 113-29.

38. Englhart S, Jubanski J, Siegert F. Quantifying dynamics in tropical peat swamp Forest biomass with multi-temporal LiDAR datasets.
Remote Sens. 2013;5:2368-88 http://www.mdpi.com/2072-4292/ $5 / 5 / 2368$.

39. Meyer V, Saatchi SS, Chave J, Dalling JW, Bohlman S, Fricker GA, et al. Detecting tropical forest biomass dynamics from repeated airborne lidar measurements. Biogeosciences. 2013;10:542138.

40. Næsset E, Bollandsås OM, Gobakken T, Gregoire TG, Ståhl G. Model-assisted estimation of change in forest biomass over an 11year period in a sample survey supported by airborne LiDAR: A case study with post-stratification to provide "activity data." Remote Sens Environ. Elsevier Inc.; 2013;128:299-314. https:// doi.org/10.1016/j.rse.2012.10.008

41. Huang W, Sun G, Dubayah R, Cook B, Montesano P, Ni W, et al. Mapping biomass change after forest disturbance: Applying LiDAR footprint-derived models at key map scales. Remote Sens Environ. Elsevier Inc. 2013;134:319-32. https://doi.org/10. 1016/j.rse.2013.03.017.

42. Andersen HE, Reutebuch SE, McGaughey RJ, d'Oliveira MVN, Keller M. Monitoring selective logging in western amazonia with repeat lidar flights. Remote Sens Environ. Elsevier B.V. 2014;151:157-65. https://doi.org/10.1016/j.rse.2013.08.049.

43. Skowronski NS, Clark KL, Gallagher M, Birdsey RA, Hom JL. Airborne laser scanner-assisted estimation of aboveground biomass change in a temperate oak-pine forest. Remote Sens Environ. Elsevier B.V.; 2014;151:166-74. https://doi.org/10. 1016/j.rse.2013.12.015

44. Magnussen S, Næsset E, Gobakken T. Lidar-supported estimation of change in forest biomass with time-invariant regression models. Can J For Res. 2015;45:1514-23.

45. McRoberts RE, Næsset E, Gobakken T, Bollandsås OM. Indirect and direct estimation of forest biomass change using forest inventory and airborne laser scanning data. Remote Sens Environ]. Elsevier B.V.; 2015;164:36-42. https://doi.org/10.1016/j.rse. 2015.02.018

46. Økseter R, Bollandsås OM, Gobakken T, Næsset E. Modeling and predicting aboveground biomass change in young forest using multi-temporal airborne laser scanner data. Scand J For Res. Taylor \& Francis; 2015;30:458-469. https://doi.org/10.1080/ 02827581.2015 .1024733

47. Réjou-Méchain M, Tymen B, Blanc L, Fauset S, Feldpausch TR, Monteagudo A, et al. Using repeated small-footprint LiDAR acquisitions to infer spatial and temporal variations of a highbiomass Neotropical forest. Remote Sens Environ. Elsevier Inc.; 2015;169:93-101. https://doi.org/10.1016/j.rse.2015.08.001

48. Stepper C, Straub C, Pretzsch H. Assessing height changes in a highly structured forest using regularly acquired aerial image data. Forestry. 2014;88:304-16.

49. Temesgen H, Strunk J, Andersen HE, Flewelling J. Evaluating different models to predict biomass increment from multitemporal lidar sampling and remeasured field inventory data in south-Central Alaska. Math Comput For Nat Sci. 2015;7:66-80.

50. Cao L, Coops NC, Innes JL, Sheppard SRJ, Fu L, Ruan H, et al. Estimation of forest biomass dynamics in subtropical forests using multi-temporal airborne LiDAR data. Remote Sens Environ. Elsevier Inc.; 2016;178:158-71. https://doi.org/10.1016/j.rse. 2016.03.012

51. Goodbody TRH, Coops NC, Tompalski P, Crawford P, Day KJ. Updating residual stem volume estimates using ALS- and UAVacquired stereo-photogrammetric point clouds. Int J Remote Sens. 2016;1161.

52. Ene LT, Næsset E, Gobakken T, Bollandsås OM, Mauya EW, Zahabu E. Large-scale estimation of change in aboveground biomass in miombo woodlands using airborne laser scanning and national forest inventory data. Remote Sens Environ. Elsevier Inc.; 2017;188:106-17. Available from: https://doi.org/10.1016/ j.rse.2016.10.046 
53. Zhao K, Suarez JC, Garcia M, Hu T, Wang C, Londo A. Utility of multitemporal lidar for forest and carbon monitoring: tree growth, biomass dynamics, and carbon flux. Remote Sens Environ. Elsevier; 2017;0-1. Available from: http://linkinghub.elsevier. com/retrieve/pii/S0034425717304194

54. Knapp N, Huth A, Kugler F, Papathanassiou K, Condit R, Hubbell SP, et al. Model-assisted estimation of tropical forest biomass change: a comparison of approaches. Remote Sens. 2018;10:123.

55. Poudel K, Flewelling J, Temesgen H. Predicting volume and biomass change from multi-temporal lidar sampling and remeasured field inventory data in Panther Creek Watershed, Oregon, USA. Forests. 2018;9:28. Available from: http://www.mdpi.com/19994907/9/1/28

56. Esteban J, McRoberts RE, Fernández-Landa A, Tomé JL, Næsset E. Estimating forest volume and biomass and their changes using random forests and remotely sensed data. Remote Sens. 2019;11.

57. Mauro F, Ritchie M, Wing B, Frank B, Monleon V, Temesgen H, et al. Estimation of changes of forest structural attributes at three different spatial aggregation levels in northern California using multitemporal LiDAR. Remote Sens. 2019;11.

58. Nguyen TH, Jones S, Soto-berelov M, Haywood A, Hislop S. Estimate forest biomass dynamics using multi-temporal lidar and single-date inventory data School of Science, RMIT University, Melbourne , Australia University of Twente , Enschede, The Netherlands. IGARSS 2019-2019 IEEE Int Geosci Remote Sens Symp. IEEE; 2019;7338-7341.

59. Tompalski P, Rakofsky J, Coops NC, White JC, Graham AN V, Rosychuk K. Challenges of multi-temporal and multi-sensor forest growth analyses in a highly disturbed boreal mixedwood forests. Remote Sens. 2019;11:2102. Available from: https://www. mdpi.com/2072-4292/11/18/2102

60. Price B, Waser LT, Wang Z, Marty M, Ginzler C, Zellweger F. Predicting biomass dynamics at the national extent from digital aerial photogrammetry. Int J Appl Earth Obs Geoinf. Elsevier; 2020;90:102116. Available from. https://doi.org/10.1016/j.jag. 2020.102116

61. Holmgren J, Persson Å. Identifying species of individual trees using airborne laser scanner. Remote Sens Environ. 2004;90: 415-23 Available from: http://linkinghub.elsevier.com/retrieve/ pii/S0034425703001408.

62. Hyyppä J, Hyyppä H, Leckies F, Gougeon F, Yu X, Maltamo M. Review of methods of small-footprint airborne laser scanning for extracting forest inventory data in boreal forests. Int J Remote Sens Taylor \& Francis. 2008;29:1339-66.

63. Kaartinen H, Hyyppä J, Yu X, Vastaranta M, Hyyppä H, Kukko A, et al. An international comparison of individual tree detection and extraction using airborne laser scanning. Remote Sens. 2012 [cited 2014 Jan 20];4:950-74. Available from: http://www.mdpi. com/2072-4292/4/4/950/

64. Tiede D, Hochleitner G, Blaschke T. A full GIS-based workflow for tree identification and tree crown delineation using laser scanning. C Iaprs. 2005;36:9-14. Available from: http://www.isprs. org/proceedings/xxxvi/3-w24/papers/cmrt05_tiede_et_al.pdf

65. Lee H, Slatton KC, Roth BE, Cropper WP. Adaptive clustering of airborne LiDAR data to segment individual tree crowns in managed pine forests. Int J Remote Sens. 2010;31:117-39.

66. St-Onge B, Vepakomma U. Assessing forest gap dynamics and growth using multi-temporal laser-scanner data. Int Arch Photogramm Remote Sens Spat Inf Sci. 2004;XXXVI, Par:173-8.

67. Yu X, Hyyppä J, Kaartinen H, Maltamo M. Automatic detection of harvested trees and determination of forest growth using airborne laser scanning. Remote Sens Environ. 2004;90:451-62. Available from: http://linkinghub.elsevier.com/retrieve/pii/ S0034425704000549
68. Yu X, Hyyppä J, Kukko A, Maltamo M, Kaartinen H. Change detection techniques for canopy height growth measurements using airborne laser scanner data. Photogramm Eng Remote Sensing. 2006;72:1339-48.

69. Frew MS, Evans DL, Londo HA, Cooke WH, Irby D. Measuring Douglas-fir crown growth with multitemporal LiDAR. For Sci. 2016:62:200-12.

70. Song Y, Imanishi J, Sasaki T, Ioki K, Morimoto Y. Estimation of broad-leaved canopy growth in the urban forested area using multi-temporal airborne LiDAR datasets. Urban For Urban Green. Elsevier GmbH.; 2016;16:142-9. Available from: https:// doi.org/10.1016/j.ufug.2016.02.007

71. Xiao W, Xu S, Elberink SO, Vosselman G. Individual tree crown modeling and change detection from airborne Lidar data. IEEE J Sel top Appl earth Obs remote Sens. IEEE. 2016;9:3467-77.

72. Dempewolf J, Nagol J, Hein S, Thiel C, Zimmermann R. Measurement of within-season tree height growth in a mixed forest stand using UAV imagery. Forests. 2017;8:1-15.

73. Guerra-Hernández J, González-Ferreiro E, Monleón VJ, Faias SP, Tomé M, Díaz-Varela RA. Use of multi-temporal UAV-derived imagery for estimating individual tree growth in Pinus pinea stands. Forests. 2017;8:1-19.

74. Ma Q, Su Y, Tao S, Guo Q. Quantifying individual tree growth and tree competition using bi-temporal airborne laser scanning data: a case study in the Sierra Nevada Mountains. California Int J Digit Earth. 2018;11:485-503.

75. Marinelli D, Paris C, Bruzzone L. A novel approach to 3-D change detection in multitemporal LiDAR data acquired in forest areas. IEEE Trans Geosci Remote Sens IEEE. 2018;56:3030-46.

76. Maltamo M, Mustonen K, Hyyppä J, Pitkänen J, Yu X. The accuracy of estimating individual tree variables with airborne laser scanning in a boreal nature reserve. Can J For Res. 2004;34:1791801.

77. Socha J, Hawryło P, Stereńczak K, Miścicki S. Assessing the sensitivity of site index models developed using bi-temporal airborne laser scanning data to different top height estimates and grid cell sizes. Int J Appl earth Obs Geoinf. Elsevier; 2020;91:102129. Available from. https://doi.org/10.1016/j.jag.2020.102129.

78. Skovsgaard JP, Vanclay JK. Forest site productivity: a review of the evolution of dendrometric concepts for even-aged stands. Forestry. 2008 [cited 2014 May 28];81:13-31. Available from: https://doi.org/10.1093/forestry/cpm041

79. Véga C, St-Onge B. Mapping site index and age by linking a time series of canopy height models with growth curves. For Ecol Manage. 2009 [cited 2013 Mar 10];257:951-9. Available from: http://linkinghub.elsevier.com/retrieve/pii/S0378112708008025

80. Holopainen M, Vastaranta M, Haapanen R, Yu X, Hyyppä J, Kaartinen $\mathrm{H}$, et al. Site-type estimation using airborne laser scanning and stand register data. Photogramm J Finl. 2010;22:16-32.

81. Packalén P, Mehtätalo L, Maltamo M. ALS-based estimation of plot volume and site index in a eucalyptus plantation with a nonlinear mixed-effect model that accounts for the clone effect. Ann For Sci. 2011 [cited 2014 Jun 11];68:1085-92. Available from: https://doi.org/10.1007/s13595-011-0124-9

82. Chen Y, Zhu X. Site quality assessment of a Pinus radiata plantation in Victoria, Australia, using LiDAR technology. South For a J For Sci. 2012 [cited 2014 Jun 11];74:217-27. Available from: https://doi.org/10.2989/20702620.2012.741767

83. Gopalakrishnan R, Kauffman JS, Fagan ME, Coulston JW, Thomas VA, Wynne RH, et al. Creating landscape-scale site index maps for the southeastern US is possible with airborne LiDAR and landsat imagery. Forests. 2019;10:1-22.

84. Socha J, Pierzchalski M, Bałazy R, Ciesielski M. Modelling top height growth and site index using repeated laser scanning data. For Ecol Manage. 2017;406:307-17. Available from: http:// linkinghub.elsevier.com/retrieve/pii/S0378112717308216 
85. Cieszewski CJ, Bailey RL. Generalized Algebraic Difference Approach : Theory Based Derivation of Dynamic Site Equations with Polymorphism and Variable Asymptotes. 2000;46.

86. Noordermeer L, Bollandsås OM, Gobakken T, Næsset E. Direct and indirect site index determination for Norway spruce and scots pine using bitemporal airborne laser scanner data. For Ecol manage. Elsevier; 2018;428:104-14. https://doi.org/10.1016/j.foreco. 2018.06.041.

87. Bollandsås OM, Ørka HO, Dalponte M, Gobakken T, Næsset E. Modelling site index in forest stands using airborne hyperspectral imagery and bi-temporal laser scanner data. Remote Sens. 2019;11.

88. Noordermeer L, Gobakken T, Næsset E, Bollandsås OM. Predicting and mapping site index in operational forest inventories using bitemporal airborne laser scanner data. For Ecol manage. Elsevier; 2020;457:117768. https://doi.org/10.1016/j.foreco. 2019.117768.

89. Kandare K, Ørka HO, Dalponte M, Næsset E, Gobakken T. Individual tree crown approach for predicting site index in boreal forests using airborne laser scanning and hyperspectral data. Int J Appl earth Obs Geoinf. Elsevier. 2017;60:72-82. https://doi.org/ 10.1016/j.jag.2017.04.008

90. Wulder MA, White JC, Stinson G, Hilker T, Kurz WA, Coops $\mathrm{NC}$, et al. Implications of differing input data sources and approaches upon forest carbon stock estimation. Environ Monit Assess. 2010 [cited 2013 Jul 9];166:543-61. http://www.ncbi. nlm.nih.gov/pubmed/19517261.

91. Vehmas M, Eerikäinen K, Peuhkurinen J, Packalén P, Maltamo M. Identification of boreal forest stands with high herbaceous plant diversity using airborne laser scanning. For Ecol Manag. 2009;257:46-53.

92. Vehmas M, Eerikäinen K, Peuhkurinen J, Packalén P, Maltamo M. Airborne laser scanning for the site type identification of mature boreal Forest stands. Remote Sens. 2011;3:100-16.

93. Solberg S, Kvaalen H, Puliti S. Age-independent site index mapping with repeated single-tree airborne laser scanning. Scand J for res. Taylor \& Francis; 2019;0:1-8. 2019. https://doi.org/10.1080/ 02827581.2019 .1616814$.

94. Pretzsch H. Forest Dynamics, Growth and Yield. Berlin, Heidelberg: Springer Berlin Heidelberg; 2009. p. 1-39. https:// doi.org/10.1007/978-3-540-88307-4_1

95. Falkowski MJ, Hudak AT, Crookston NL, Gessler PE, Uebler EH, Smith AMS. Landscape-scale parametrization of a tree-level forest growth model: a k-nearest neighbor imputation approach incorporating LiDAR data. Can J For Res. 2010;40:184-99.

96. Mohamedou C, Korhonen L, Eerikaïnen K, Tokola T. Using LiDAR-modified topographic wetness index, terrain attributes with leaf area index to improve a single-tree growth model in South-Eastern Finland. Forestry. 2019;92:253-63.

97. Härkönen S, Tokola T, Packalén P, Korhonen L, Mäkelä a. Predicting forest growth based on airborne light detection and ranging data, climate data, and a simplified process-based model. Can J For Res. 2013;43:364-75. http://www.scopus.com/inward/ record.url?eid=2-s2.0-84876712494\&partnerID=40\&md5= 37e4ae5648cf437a2f017dda0bfa01d0

98. Lamb SM, MacLean DA, Hennigar CR, Pitt DG. Forecasting forest inventory using imputed tree lists for LiDAR grid cells and a tree-list growth model. Forests. 2018;9:1-18.

99. Tompalski P, Coops N, White J, Wulder M. Enhancing forest growth and yield predictions with airborne laser scanning data: increasing spatial detail and optimizing yield curve selection through template matching. Forests. 2016;7:255. http://www. mdpi.com/1999-4907/7/11/255

100. Tompalski P, Coops N, Marshall P, White J, Wulder M, Bailey T. Combining multi-date airborne laser scanning and digital aerial photogrammetric data for forest growth and yield modelling.
Remote Sens. 2018;10:347. http://www.mdpi.com/2072-4292/ $10 / 2 / 347$

101. Ministry of Forest Lands and Natural Resource Operations. Growth and Yield Modelling. 2015 [cited 2015 Jun 10]. https:// www.for.gov.bc.ca/hts/growth/tipsy/tipsy_description.html

102. Huang S, Meng SX, Yang Y. A Growth and Yield Projection System (GYPSY) for natural and post-harvest stands in Alberta. For Div Alberta Sustain Resour Dev Tech Rep. 2009;T/216:1-22.

103. Marczak PT, Van Ewijk KY, Treitz PM, Scott NA, Robinson DCE. Predicting carbon accumulation in temperate forests of Ontario. Canada Using a LiDAR-Initialized Growth-and-Yield Model Remote Sens. 2020;12:201.

104. Saad R, Eyvindson K, Gong P, Lämås T, Ståhl G. Potential of using data assimilation to support forest planning. Can J For Res 2017;47:690-695. https://doi.org/10.1139/cjfr-2016-0439

105. Nyström M, Lindgren N, Wallerman J, Grafström A, Muszta A, Nyström K, et al. Data assimilation in forest inventory: first empirical results. Forests. 2015;6:4540-57.

106. Ehlers S, Saarela S, Lindgren N, Lindberg E, Nyström M. Assessing error correlations in remote sensing- based predictions of forest attributes for improved data assimilation. 2017;

107. Hou Z, Mehtätalo L, McRoberts RE, Ståhl G, Tokola T, Rana P, et al. Remote sensing-assisted data assimilation and simultaneous inference for forest inventory. Remote Sens environ. Elsevier; 2019;234:111431. Available from. https://doi.org/10.1016/j.rse. 2019.111431.

108. Ehlers S, Grafström A, Nyström K, Olsson H, Ståhl G. Data assimilation in stand-level forest inventories. Can J For Res. 2013;43:1104-13 http://apps.webofknowledge.com/full_record. do? product $=$ UA\&search $\_$mode $=$GeneralSearch $\&$ qid $=11 \& \mathrm{SID}=$ V183QrlvsKq8NFzUI2y $\overline{\text { \&page }}=1 \&$ doc $=1$.

109. Welch G, Bishop G. An Introduction to the Kalman Filter. Tech report UNC-CH Comput Sci Tech Rep 95041. 1995;133-40. http://www-flare.cs.ucl.ac.uk/staff/S.Prince/4C75/ LaceyThackerTutorial.pdf

110. Fekety PA, Falkowski MJ, Hudak AT. Temporal transferability of LiDAR-based imputation of forest inventory attributes. Can J For Res. 2015;45:422-35. https://doi.org/10.1139/cjfr-2014-0405

111. Roussel JR, Caspersen J, Béland M, Thomas S, Achim A. Removing bias from LiDAR-based estimates of canopy height: Accounting for the effects of pulse density and footprint size. Remote Sens Environ. Elsevier Inc.; 2017;198:1-16. https://doi. org/10.1016/j.rse.2017.05.032

112. Baltsavias EP. A comparison between photogrammetry and laser scanning. ISPRS J Photogramm Remote Sens. 1999 [cited 2013 Dec 23];54:83-94. http://www.sciencedirect.com/science/article/ pii/S0924271699000143

113. Remondino F, Spera MG, Nocerino E, Menna F, Nex F. State of the art in high density image matching. Photogramm Rec. 2014;29:144-66. https://doi.org/10.1111/phor.12063.

114. Vastaranta M, Niemi M, Wulder MA, White JC, Nurminen K, Litkey $\mathrm{P}$, et al. Forest stand age classification using time series of photogrammetrically derived digital surface models. Scand J For Res. 2016;31:194-205.

115. Babcock C, Finley AO, Cook BD, Weiskittel A, Woodall CW. Modeling forest biomass and growth: Coupling long-term inventory and LiDAR data. Remote Sens Environ. Elsevier Inc.; 2016;182:1-12. https://doi.org/10.1016/j.rse.2016.04.014

116. Næsset E. Estimating above-ground biomass in young forests with airborne laser scanning. Int J Remote Sens. 2011;32:473-501.

117. Maltamo M, Packalén P, Suvanto A, Korhonen KT, Mehtätalo L, Hyvönen P. Combining ALS and NFI training data for forest management planning: a case study in Kuortane. Western Finland Eur J For Res. 2009;128:305-17. https://doi.org/10. 1007/s10342-009-0266-6. 
118. Racine EB, Coops NC, St-onge B, Begine J. Estimating forest stand age from LiDAR-derived predictors and nearest neighbor imputation. For Sci. 2014;60:1-9.

119. Wylie RRM, Woods ME, Dech JP. Estimating stand age from airborne laser scanning data to improve models of black spruce wood density in the boreal forest of Ontario. Remote Sens. 2019;11.

120. Ørka HO, Dalponte M, Gobakken T, Næsset E, Ene LT. Characterizing forest species composition using multiple remote sensing data sources and inventory approaches. Scand J For Res]. Taylor \& Francis. 2013;28:677-88. https://doi.org/10.1080/ 02827581.2013 .793386

121. Budei BC, St-Onge B, Hopkinson C, Audet FA. Identifying the genus or species of individual trees using a three-wavelength airborne lidar system. Remote Sens environ. Elsevier; 2018;204: 632-47. https://doi.org/10.1016/j.rse.2017.09.037.

122. Lefsky MA, Turner DP, Guzy M, Cohen WB. Combining lidar estimates of aboveground biomass and Landsat estimates of stand age for spatially extensive validation of modeled forest productivity. Remote Sens Environ. 2005;95:549-58. http://linkinghub. elsevier.com/retrieve/pii/S0034425705000258
123. Hermosilla T, Wulder M, White JC, Coops N, Hobart GW. An integrated Landsat time series protocol for change detection and generation of annual gap-free surface reflectance composites. Remote Sens Environ. 2015;158:220-34.

124. Matasci G, Hermosilla T, Wulder MA, White JC, Coops NC, Hobart GW, et al. Three decades of forest structural dynamics over Canada's forested ecosystems using Landsat time-series and lidar plots. Remote Sens environ. Elsevier. 2018;216:697714. https://linkinghub.elsevier.com/retrieve/pii/ S0034425718303572.

125. Ayrey E, Fraver S, Kershaw JA, Kenefic LS, Hayes D, Weiskittel AR, et al. Layer stacking: a novel algorithm for individual forest tree segmentation from LiDAR point clouds. Can J Remote Sens. 2017;43:16-27. https://doi.org/10.1080/07038992.2017. 1252907.

Publisher's Note Springer Nature remains neutral with regard to jurisdictional claims in published maps and institutional affiliations. 